\title{
Oscillatory Nature of the Magnetosphere \\ II. The EM-Background, Strong Packets of Waves, Resonances
}

\author{
Ya. ALPERT ${ }^{1}$ and L. J. LANZEROTTI ${ }^{2}$ \\ ${ }^{1}$ Harvard Smithsonian Center for Astrophysics, Bell Laboratories, Lucent Technologies, U.S.A. \\ ${ }^{2}$ Bell Laboratories, Lucent Technologies, U.S.A.
}

(Received August 22, 1995; Revised April 10, 1997; Accepted April 10, 1997)

\begin{abstract}
A new approach toward an understanding of the nature of ULF-ultra low frequency-em. waves observed in the magnetosphere is given in this paper. The work is based upon results derived from detailed studies of the Fourier spectra of experimental magnetic field data obtained at a number of different geomagnetic locations around the world: Cascade $(L=2.9$; Iowa, U.S.A.); Iqaluit - NP $(L=13$; Northwest Territories, Canada), Amundsen-Scott Station - SP ( $L=13$; Antarctica), and also at Tuckerton $(L=2.6$; New Jersey), and Point Arena ( $L=2.6$; California). The frequency band of the examined oscillations is $F \simeq\left(0.7 \cdot 10^{-3}-5 \cdot 10^{-2}\right) \mathrm{Hz}$ and overlaps the frequencies of the so-called (Pc2-Pc5) micropulsations. We show that the em. oscillations of these packets of waves exist in any time both in quite and disturbed conditions in the em. background of the magnetosphere. They appear to be resonance oscillations occurring in the magnetosphere on the whole or on its parts. During the intervals studied, in the examined frequency range 12 fundamental resonance frequencies were found in the spectra of the NP and SP data and more than 20-25 resonance frequencies in the Tuckerton and Point Arena data.* The other resonance maxima disappear in the weak oscillations of the noise. In general, the em. background of the magnetosphere is of a "lined" structure. It is composed of the resonance oscillations (frequency maxima of its spectra), and by more weak oscillations-by noise. All these oscillations can be set swinging, producing isolated, short-lived packets of waves. The conditions for producing the swinging can be impulse/shock - excitations of the magnetospheric plasmas, swinging of the background oscillations by gyro-resonance instability, dynamic effects such as changes in the neutral winds, etc. Thus, the wellknown multiple manifestations of hydromagnetic ULF waves and wave packets observed in the magnetosphere are considered to be the result of a single physical phenomenon: the fundamental em. oscillatory nature of the background magnetospheric plasma environment.
\end{abstract}

\section{Introduction}

One of the fundamental properties of the magnetosphere is its em. oscillatory background. These irregular oscillations exist continuously as well as, for example, the Brownian thermal movement of particles in fluids. In an earlier paper (Alpert et al., 1993) we have shown for an interval of geomagnetic disturbance, that the hydromagnetic background of the magnetosphere analyzed from data at Cascade, IL $(L=2.9$ ) was composed of a number of narrow bands of oscillations of different frequencies. The frequencies $F_{s, \max }$ of these bands were found by a detailed Fourier analysis of filtered and unfiltered time records of different components of the Earth's magnetic field $B_{\mathrm{E}}(t)$ in the frequency band $F \leq(0.01-0.26)$ $\mathrm{Hz}$. While it was found that the values $F_{s, \max }$ of these spectral lines were more or less stable during the observation interval, their amplitudes $B_{s, \max }$ could be quite variable. However, in some intervals $B_{s, \max }(t)$ could grow by a factor of 10 to 100 , and even more within a few minutes: $B_{s, \text { max }}$ could approach a maximum

*The results of Tuckerton and Point Arena will be presented in detail in another paper. The values of the resonance frequencies from both of those stations are given in the paper for comparison (see page 9 and Eq. (8), page 16). 
$\operatorname{Max}\left(B_{s, \max }\right)$ and then return to near background level. The envelope of $B_{s, \max }(t)$ at such times was found to be of a resonance shape, with a duration $\tau_{s} \sim(3-8) \mathrm{min}$.

For illustration, in Fig. 1 the amplitudes $\left|B_{s, \max }\right|$ of five $(s=5)$ narrow bands $F_{0}, F_{\mathrm{II}}, F_{\mathrm{III}}, F_{\mathrm{IV}}, F_{\mathrm{V}}$ observed at Cascade are shown (adopted from Alpert et al., 1993). The frequency of one of them, namely of $F_{0}(t)$ is about $0.012 \mathrm{~Hz}$. It is very stable and close to the frequency of the first maximum of a spectrum of a rectangular impulse with $\tau=120$ s; i.e. of the window used in the Fourier analysis, which is equal to $F=(1.4303 / 120 \mathrm{~s})=0.01192 \mathrm{~Hz}$. About 50 spectra were calculated for successive $\tau=120 \mathrm{~s}$ intervals overlapped by 30 and 60 seconds. It is seen from the figure that the most active band was $F_{\text {III; }}$ it has three distinguishable maxima. The amplitude of the strongest of these signals $\left(F_{\mathrm{I}}=0.133 \mathrm{~Hz}\right)$, namely that of a unique Pc2 pulsation event reported by Lanzerotti et al. $(1983,1986)$ increased to about 400 times larger than the amplitude of the background. Five weaker packets of waves with values $\operatorname{Max}\left(F_{s, \max }\right) \sim(0.113-$ $0.226)) \mathrm{Hz}$ were also observed. These maxima are denoted in $F i g .1$ by $F_{2}, F_{3}, F_{4}, F_{5}, F_{6}$. Two more maxima $F_{1}{ }^{\prime}$ and $F_{2}{ }^{\prime}$ were observed from a splitting of the narrow band $F_{\text {III }}$ into two. Such a bifurcation process was observed at Cascade and was also evident in the data described below.

In their discussion, Alpert et al. (1993) showed that the $F_{s \text {, max }}$ of the narrow bands could be considered to be spectral maxima of short-lived impulse-like disturbances of more or less rectangular shape. Further, for the interval and frequencies analyzed, Alpert et al. concluded that the origin of the observed phenomena is the gyro-resonance instability of the magnetoplasma

$$
\left(k \cdot V_{\|}\right)=\omega_{\mathrm{res}}+\Omega_{B}, \quad k=\frac{\omega_{\mathrm{res}}}{c} \cdot n .
$$

That is, they assumed that the amplitude of the oscillations of the appropriate band $F_{s}$ of the background is swinging/amplified during the times $t=\tau_{s}$ when the frequency $F_{s, \max }$, step by step, approached and became even equal to the gyro-resonance frequency $F_{\text {res. }}$. When $F<<F_{B}$

$$
F_{\text {res }}=\frac{c}{V_{\|}} \cdot \frac{F_{B}^{2}}{F_{0}} \sim \frac{B^{2}(t)}{V_{\|}(t) \sqrt{N_{0}(t)}} .
$$

In Eqs. (1) and (2) $V_{\|}$is the longitudinal velocity of the hot directed stream of ions, $\omega_{\mathrm{res}}=2 \pi \cdot F_{\mathrm{res}}, \Omega_{B}=$ $2 \pi \cdot F_{B} . F_{B}$ is the gyro-frequency of ions, $k$ is the wave number, $n=n_{\mathrm{A}}$ is the refraction index, $n_{\mathrm{A}}=\Omega_{0} / \Omega_{B}$ is the so called Alfven coefficient of refraction, $\Omega_{0}=2 \pi \cdot F_{0}=\left(\left(4 \pi \cdot N \cdot e^{2}\right) / M\right)^{1 / 2}$ is the angular ion Langmuir frequency, $\mathrm{c}$ is the velocity of em. waves in free space, $B$ is the magnetic field, $N_{0}$ and $M$ are the density and the mass of the ions. It is emphasized in Eq. (2) that all the parameters of the plasma are changing in time.

From the results of Alpert et al. (1993) it became clear that it is important to examine further this phenomenon of oscillations in the background magnetoplasma and their swinging, and to learn:

- if the discussed phenomena are truly fundamental characteristics of the magnetosphere;

- what is the physical nature/origin of the narrow oscillatory bands of the background and strong packets of waves;

- what the mechanisms of amplification/swinging of the background oscillations consist of.

Some results of our research on these problems are given in this and future papers.

Through an analysis of a large volume of experimental data, we found, in summary, the following. In the frequency band of Pc2 to Pc5 micropulsations for $F \leq(0.7-50) \mathrm{mHz}$, the recorded oscillations of the magnetic field are composed of 12 narrow frequency bands. The frequencies are rather stable. During the analyzed interval: $F_{s, \max }(t)=\overline{F_{s, \max }} \cdot(1 \pm 0.03)$ to $F_{s, \max }(t)=\overline{F_{s, \max }} \cdot(1 \pm 0.2), s=1,2,3, \ldots, 12$. In the intervals of the swinging processes of the background oscillations, when $B_{s, \max }$ grows by a factor of 10 or more, strong packets of waves were produced with $\tau_{s} \simeq(15-30)$ min. The values of $B_{s, \max }$ of these bands 

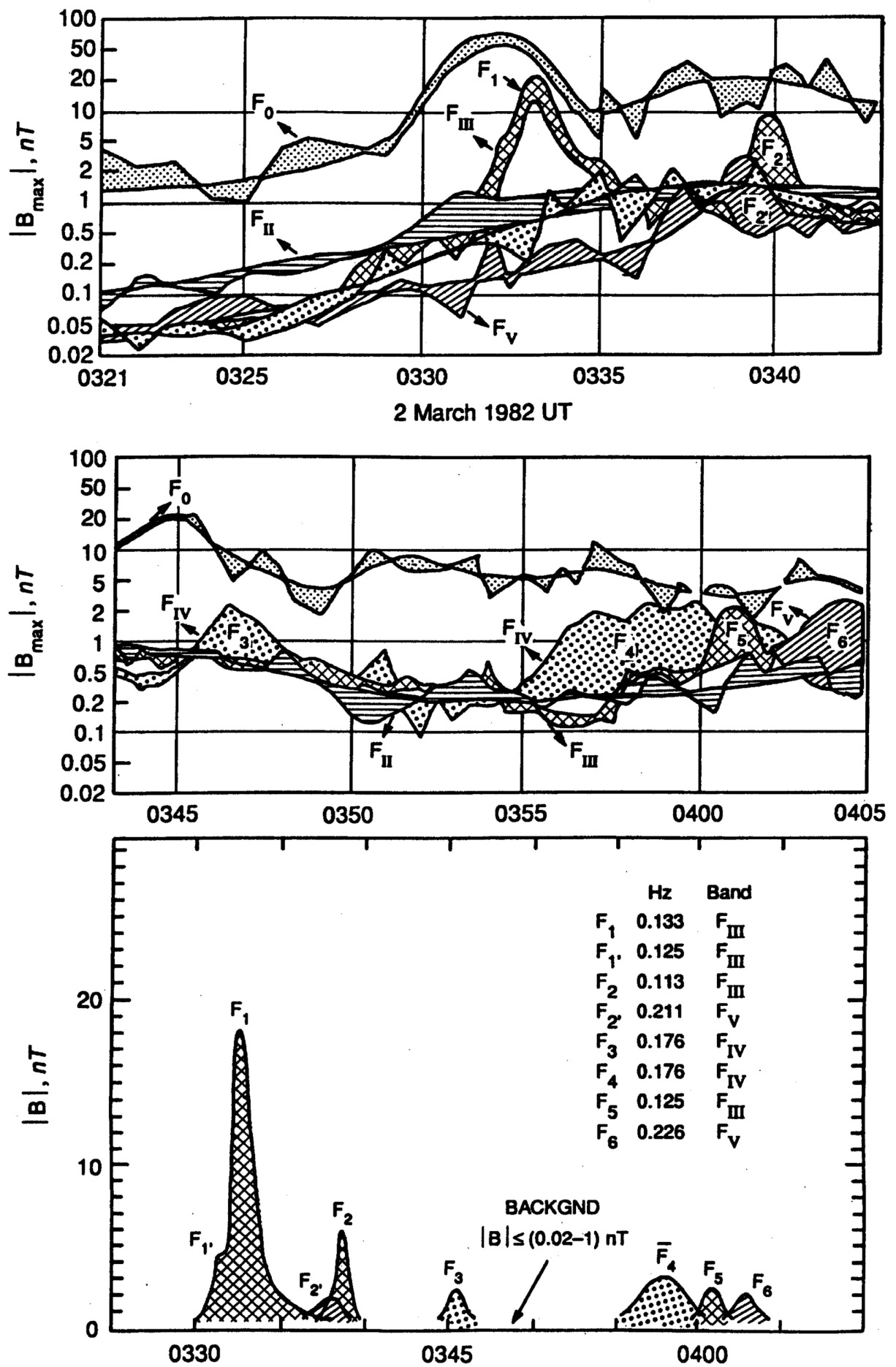

Fig. 1. Variations of the spectra maxima $B_{s, \max }$ of five distinguished frequency bands observed at Cascade during the time $3 \mathrm{~h} 21 \mathrm{~m}$ to $4 \mathrm{~h} 05 \mathrm{~m}$ UT. The identified frequency bands are $F_{0}$ to $F_{\mathrm{V}}$, the $F_{1}$ to $F_{6}$ correspond to the distinguished maxima of the amplified packets of waves. 
change rapidly and irregularly (see below, Section 3 ). The same frequency bands were found in the spectra of the filtered and unfiltered records. In some cases the resonance shape of $B_{s \text {, max }}(t)$ of these oscillations is rather striking. However, in general, the shape of the envelopes of the filtered oscillations $B(t)$ are variable and complicated because these packets of waves are composed of two, three, or more narrow band oscillations $F_{s, \max }$ whose frequencies are incommensurable.

Thus, the principal conclusion of our study is that the values $F_{s, \max }$ can be the resonance frequencies (the eigenvalues) of a magnetospheric oscillatory system, perhaps of the magnetospheric cavity. These oscillations exist continuously in the background plasma environment, a concept noted earlier by Alpert and Fligel (1985), and Alpert (1987). The swinging of the background frequencies occurs due to the excitation of the magnetospheric plasma by disturbances that can be produced by a variety of sources such as impulse/shock hits, through the flow of the solar wind around the magnetosphere, by the gyroresonance instability of the magnetoplasma, and perhaps also by internal dynamic effects such as changes in the neutral "winds" in the plasma drift (see Alpert and Lanzerotti, 1998).

It follows that the observed variety of Pc2 to Pc5 packets of waves can be produced in the magnetosphere by a single mechanism. They result from the fundamental resonance oscillations of a magnetospheric oscillating system that has a continuum of degrees of freedom, $s=1,2, \cdots$. The idea of the possible connection between the ultra low frequency waves, observed in the magnetosphere, with resonance oscillations of the magnetospheric system has a long history, originating with Dungey (1954). It was discussed by many authors. Some authors considered that the origin of these waves may be the resonance oscillations of the magnetosphere - of the magnetospheric cavity. In other studies the flux tube produced along the curved magnetic field lines, which guide the em. waves from the apogee of their trajectory to the observer at the Earth were regarded as the appropriate resonance systems. Even the Earth's magnetic field tail has been discussed as such a system. A limited set of important historical papers include those of Watanabe (1959, 1961), Obayashi (1965), Patel (1965, 1968), Dungey (1968), Radoski (1967a, b, 1971), Brjunelli and Namgaladze (1969), McClay (1969), Ershkovich and Nusinov (1971), Orr and Mathew (1973), Russell et al. (1972), McPherron et al. (1972), Southwood (1974, 1975); Chen and Hasegawa (1974a, b), Fukunishi and Lanzerotti (1974a, b), Polyakov et al. (1981), Krylov and Lifshits (1983), Belyaev et al. (1984), Kivelson and Southwood (1985, 1986), Rickard and Wright (1994), and many others. A review including many references is, for example, by Gulelmi and Troitskaya (1973) (see also Cummings et al. (1962)). However, both theoretically and experimentally the problem of the existence in the magnetosphere of eigenvalues ULF resonances remains open until now.

In some of the cited papers the frequencies of the observed magnetospheric ULF em. waves were considered to be resonance frequencies of the magnetosphere. In the papers by Alpert and Fligel (1985, 1987), and Alpert et al. (1989) the resonance frequency bands were identified with symmetrical maxima of the spectra, relatively to the carrier frequencies of the packets of waves of Pcl micropulsations. These maxima could appear due to the amplitude modulation of the Pcl packets of waves by the resonance oscillations. However, by appropriate sequential examination of experimental data, the resonance oscillations of the magnetosphere originating from the background were studied in this our paper (see also Alpert and Lanzerotti, 1998).

The experimental data used in this paper were recorded with 3-axis fluxgate magnetometer systems at Amundsen Scott, Antarctica (SP, $L=13$ ), and Iqaluit, North West Territories, Canada (IQ - NP, $L=13$ ). These stations are approximately conjugate with approximately the same magnetic local time. The instrumentation has been described previously in a number of papers.

\section{Data Set}

The intensity records of both the unfiltered $H(t)$ components of the magnetic field $B_{\mathrm{E}}(t)$ and the moduli $\sqrt{H(t)^{2}+D(t)^{2}+Z(t)^{2}}$ of the filtered (30-40) s magnetic field oscillations observed at the IQ and SP stations are shown in Fig. 2 for a two hour interval prior to local midnight (MLT $=U T-4 \mathrm{~h}$ ). These records 
in essence illustrate the "climate" of the magnetosphere at these locations at the time of the measurements. Here the geomagnetic south-north, west-east, and vertical components are denoted $H(t), D(t)$, and $Z(t)$, respectively. A right-handed (left-handed) coordinate system is used in the northern (southern) hemisphere.

The data in Fig. 2 show that following a thirty minute interval of geomagnetic quiet, depressions ("bays") were observed in the $H$-component records at both SP and IQ. These decreases in the geomagnetic field, corresponding to three enhancements of the overhead ionospheric currents above the near-conjugate
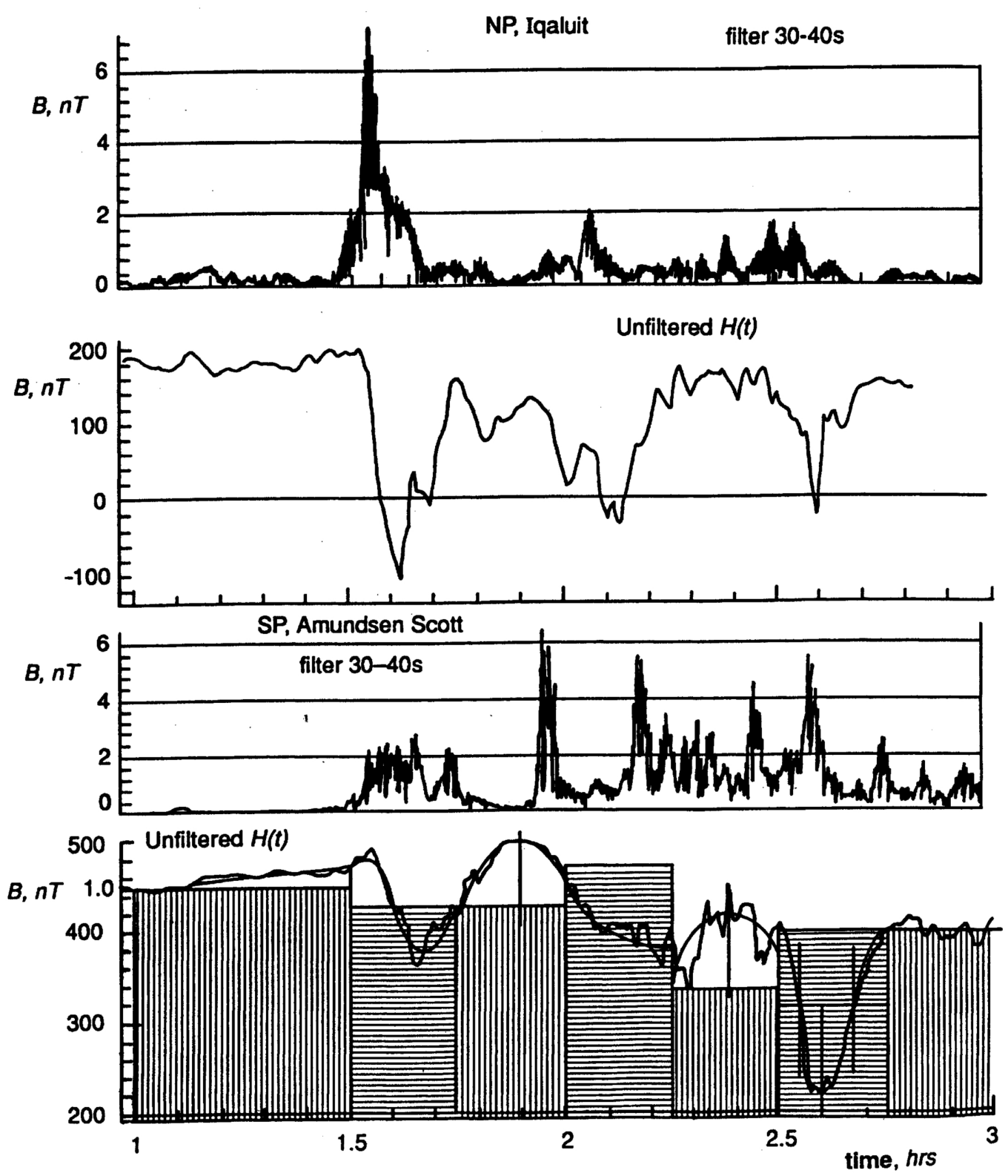

Fig. 2. The time dependencies of the $H(t)$ component of the unfiltered magnetic field $B(t)$, and of the moduli of the filtered oscillations by a filter $\Delta t_{f}=(30-40) \mathrm{s}$, observed at the North (IQ) and South Pole (SP) stations. 
stations, were larger in the northern hemisphere than in the southern. Beginning with the first increase of the ionospheric currents, the moduli of the magnetic field oscillations in the filtered (30-40) s band, namely within the so-called Pc3 band of micropulsations, increased substantially at both locations from the small amplitudes that were observed in the interval 0100-0130 UT. The initial increase of the filtered modulus signal was larger at IQ than at SP while subsequent enhancement in the amplitudes tended to be larger at SP.

The filtered $H(t)$ and $D(t)$ components (see Fig. 3) for the band (30-40) s show that the quiet periods occur at SP and IQ at essentially the same time: $t \sim 0100$ to $\sim 0130-0135$ UT. A strong packet of waves with duration $\tau \sim 20$ min was seen at both locations at $t \sim 0130-0150$ UT. Both the small amplitude variations in the filtered band prior to the first increase in ionospheric currents and the relative amplitudes of the filtered signals at both stations are evident: the first onset of increased amplitudes are a factor of two larger at IQ than at SP and of somewhat shorter duration overall. Throughout the remainder of the two hour interval the southern station signals are larger than those in the north and are of more continuing duration.

Certainly, after this observation of the filtered (30-40) s oscillations, it was important to examine the evolution of the moduli of the filtered magnetic field in the entire frequency band of the observations, namely of the packets of waves which are often distinguished in the literature by different nomenclature;
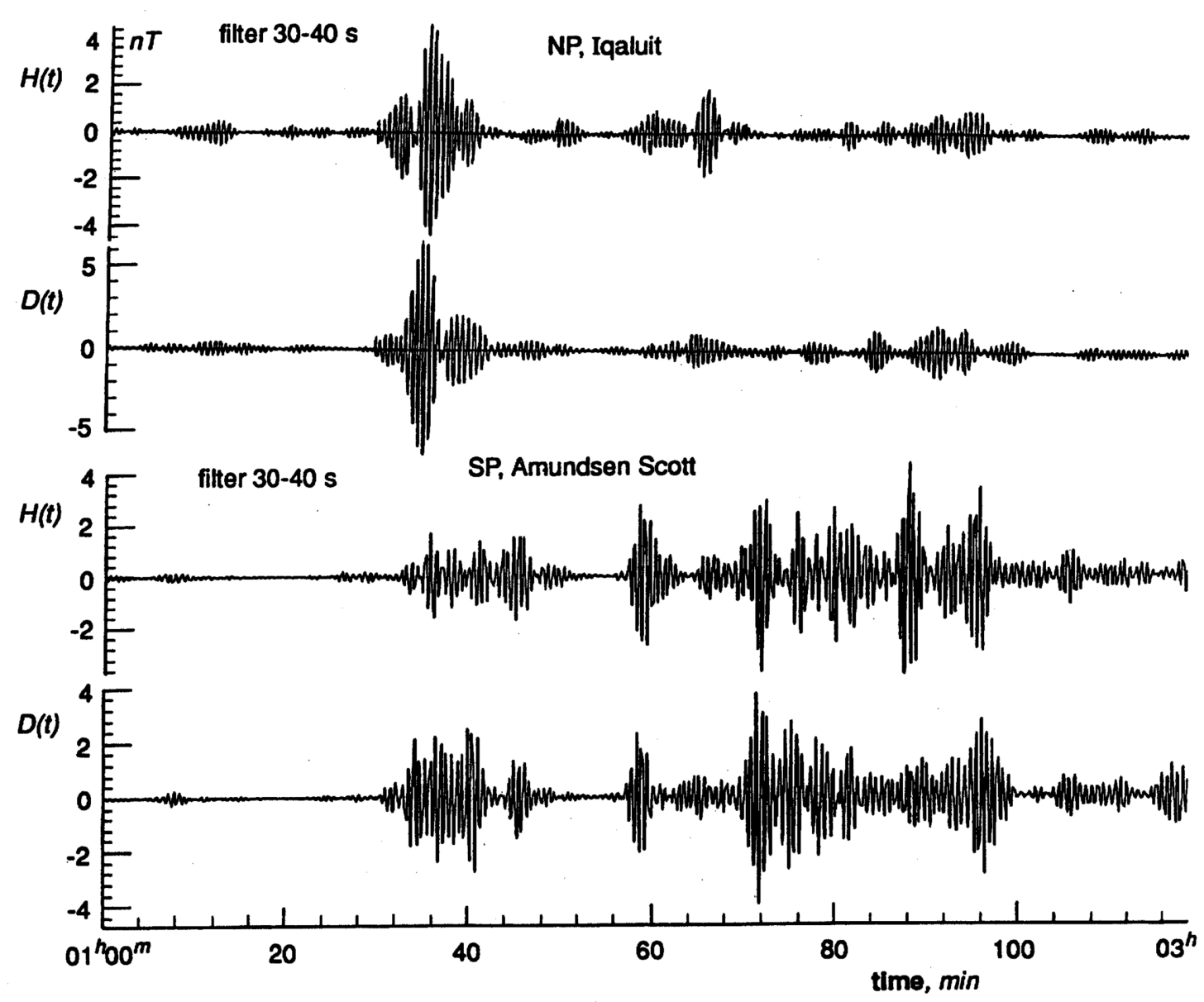

Fig. 3. Filtered oscillations of the $H(t)$ and $D(t)$ components in the frequency band $\Delta F_{f} \simeq(0.025-0.033) \mathrm{Hz}$, observed at the NP and SP stations. 


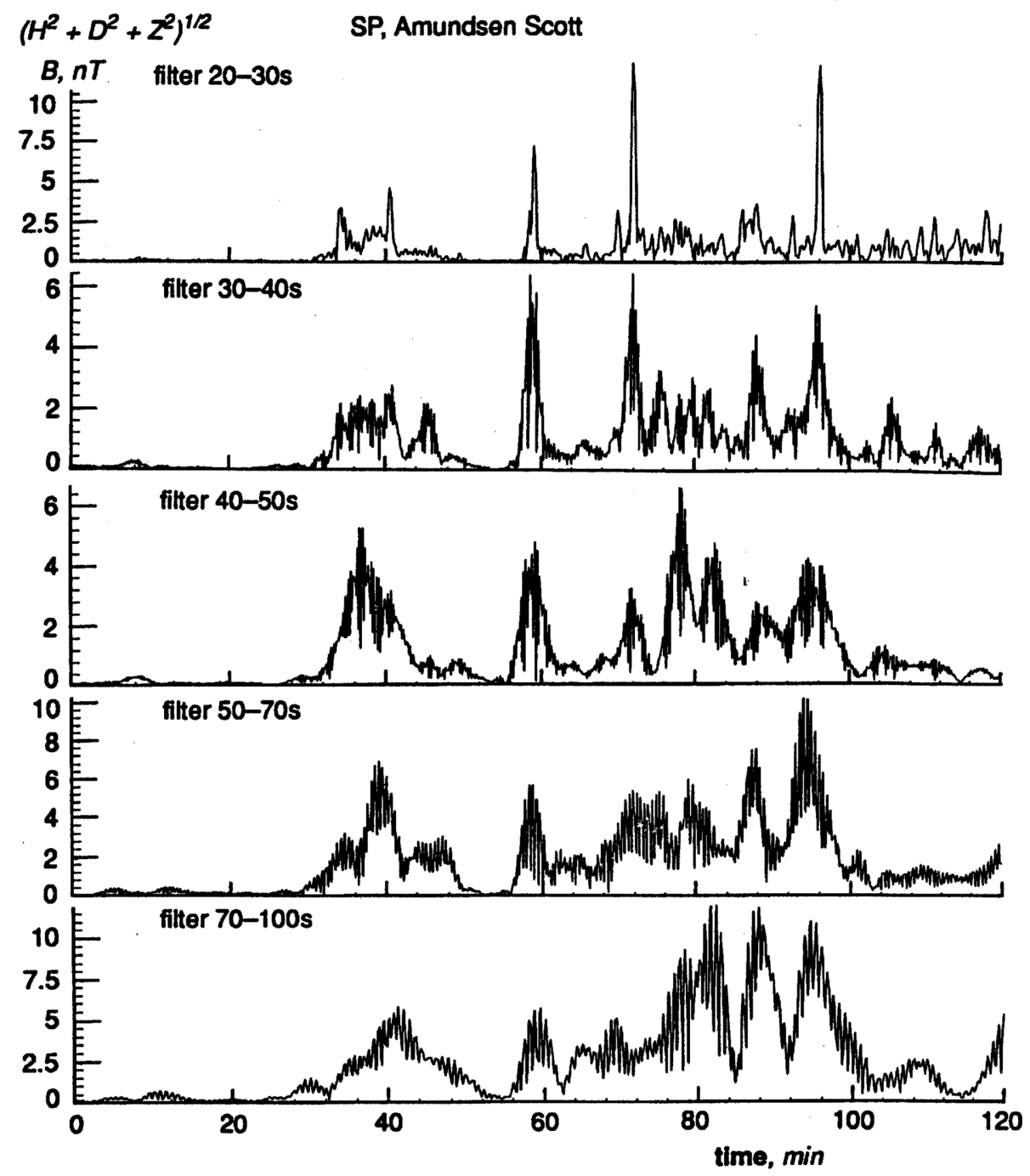

Fig. 4. Moduli of filtered oscillations by the filters $\Delta t_{f}=[(20-30),(30-40),(40-50),(50-70),(70-100)]$ sec in the frequency band $F \simeq(10-50) \mathrm{MHz}$, observed at the SP station.

e.g. Pc2, Pc3, Pc4, and Pc5. The appropriate moduli of the SP data are shown in Fig. 4 for the filter bands

$$
\Delta \tau_{\mathrm{f}}=(20-30) \mathrm{s},(30-40) \mathrm{s},(40-50) \mathrm{s},(50-70) \mathrm{s},(70-100) \mathrm{s},
$$

and in Fig. 5 for overlapped filter bands

$$
\Delta \tau_{\mathrm{f}}=(20-40) \mathrm{s},(30-50) \mathrm{s},(40-100) \mathrm{s},(80-300) \mathrm{s},(200-1500) \mathrm{s} .
$$

These filters cover a large frequency range

$$
F \simeq(0.7-50) \mathrm{mHz}
$$



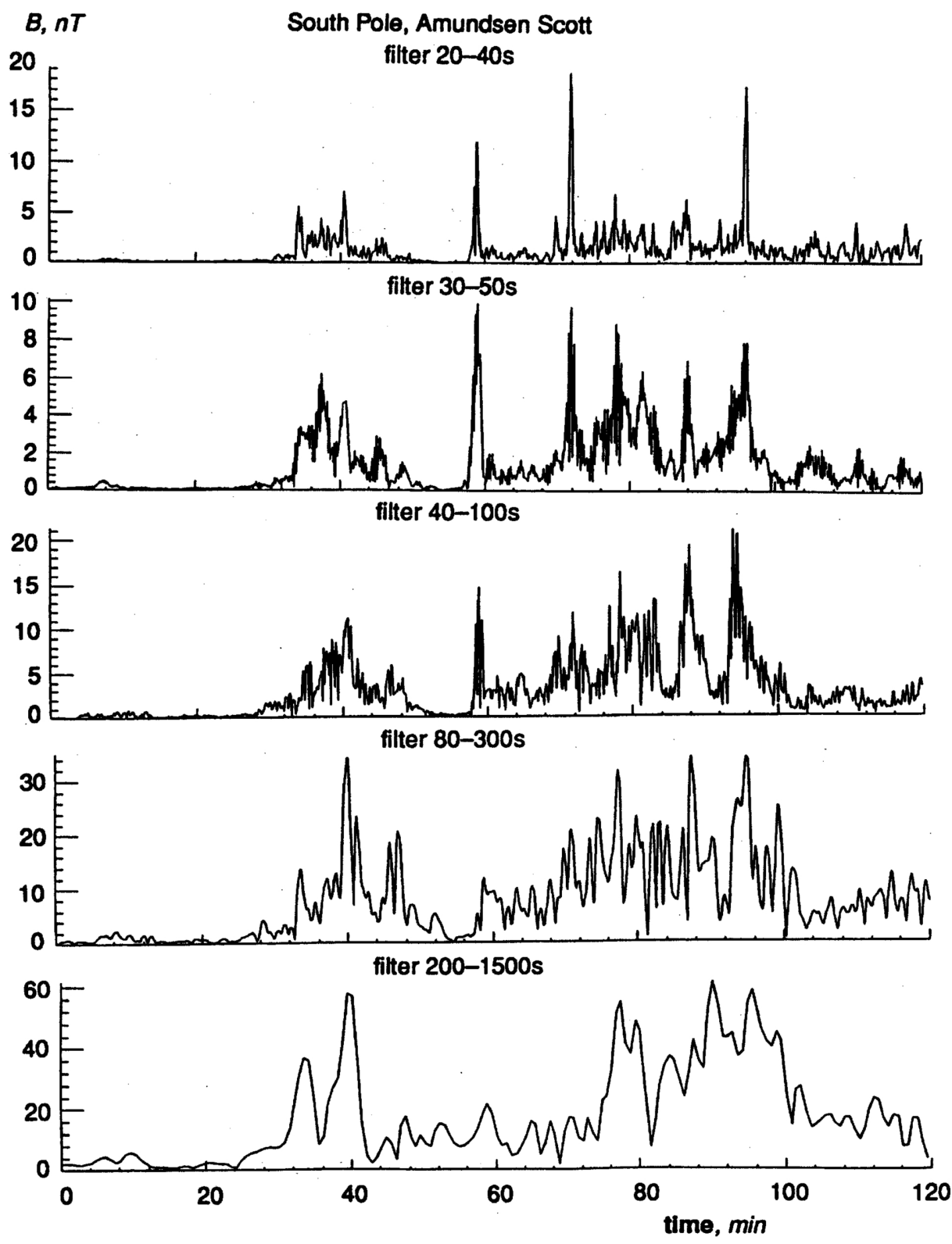

Fig. 5. Moduli of filtered oscillations by overlapped filters $\Delta t_{f}=[(20-40),(30-50),(40-100),(80-300),(200-1500)]$ sec in the frequency band $F \simeq(0.066-50) \mathrm{MHz}$, observed at the SP station.

of em. waves with frequencies $F \ll F_{B}$; i.e. much smaller than the ion gyro-frequencies of the local regions of the magnetosphere where these waves were generated.

The following crucial inference follows directly from these figures and from similar moduli dependencies obtained at the IQ (NP), and at the Tuckerton and Point Arena stations. The main properties of the variations in time of the filtered oscillations shown in Figs. 2 to 5 are the same; their shapes are rather similar. Namely, the durations of the long and short quiet time periods of oscillation - the background periods - are very close in all the filtered bands. The periods $\tau_{s}$ of the individual strong packets of waves 
are also very close. The same similarity is observed during the irregular disturbed period of time $t \simeq 0150$ to $\mathbf{0 3 0 0}$. However, the so-called micropulsations with different designations have often been considered to be signals of a different nature, generated by different mechanisms. Such a point of view is immediately in contradiction with the data shown. On the contrary, these data suggest that all the filtered packets of waves are generated by a single mechanism; that is, they are of a similar nature. To understand more completely the nature of these data, we examined in detail their frequency composition, as discussed in the next section.

3. Frequency Composition of the Magnetic Field Variations in the Frequency Band $F=(0.67-50) \mathrm{MHz}$

We studied the time evolution of the Fourier spectra during the two hour interval. Both unfiltered and filtered magnetic field records were examined for several bands as is shown in Figs. 4 and 5. Twenty two spectra overlapped by 5 minutes in time blocks of $\Delta t_{\mathrm{F}}=15 \mathrm{~min}$ were calculated. In many cases the spectra were calculated for $\Delta t_{\mathrm{F}}=5$ and $7.5 \mathrm{~min}$. On the whole, about 200 spectra were examined. These results are given in Figs. 6 to 12 and in some tables in Appendix.

Examples of such Fourier spectra for unfiltered and filtered data are shown respectively in the lefthand column and four right columns for three 15 minutes intervals in Fig. 6, and Tables A-I to A-III. The spectra of the unfiltered magnetic field fluctuations are especially important. The top panel in the lefthand column of Fig. 6 corresponds to the spectrum of the unfiltered magnetic field fluctuations during the first 15 minutes of the analyzed interval when the geomagnetic field was relatively quiet. The central panel corresponds to the first large enhancement in signals at the time of the first ionospheric current enhancement: The lowest panel of the unfiltered spectra is for data obtained during the second ionospheric current enhancement, when the filtered data amplitudes again become large (see Fig. 2). The Fourier spectra in Fig. 6 are composed of a series of peaks of various amplitudes. Some results given in Figs. 7 , 8, and Table A-I of Appendix show the following:

- Twelve regular frequency maxima $F_{s, \max }, s=1, \ldots, 12$ appear in these spectra. Their variations with time are shown on Fig. 7. Not all the twelve maxima appear in each time interval $\Delta t_{\mathrm{F}}=15 \mathrm{~min}$. In addition, bifurcation of some maxima is often observed.

- The values of $F_{s, \max }$ are rather stable throughout the time intervals analyzed. Their most probable values are equal to

$$
F_{s, \max } \simeq \overline{F_{s, \max }}[(1 \pm 0.03) \text { to }(1 \pm 0.11)]
$$

and the mean values obtained from the data of the NP and SP stations $(L=13)$ are equal to

$$
\overline{F_{s, \max }} \simeq(5.2,9.2,14,17,20,24,28,32,35,38,42,46) \mathrm{mHz} .
$$

From the data of Tuckerton and Point Arena these first 12 maximal frequencies are, respectively, equal to

$$
\begin{aligned}
& \overline{F_{s, \max }} \simeq(11,19,27,34,40,49,58,67,74,80,89,97) \mathrm{mHz} . \\
& \overline{F_{s, \max }} \simeq(11.8,20,29,39,45,53,61,69,77,88,96,104) \mathrm{mHz} .
\end{aligned}
$$

It is seen that the values of $F_{s, \max }$ obtained from the data of these stations $(L=2.6)$ are sufficiently similar. Of course, they should not be the same and differ from the values of Eq. (7). We have to note here that values $\overline{F_{s, \max }} \simeq(11,22,35,47) \mathrm{MHz}$ (see Eq. (7)) were also found by Alpert et al. $(1985$ and 1989) in an examination of Fourier spectra of Pcl micropulsations. These frequencies were considered as 


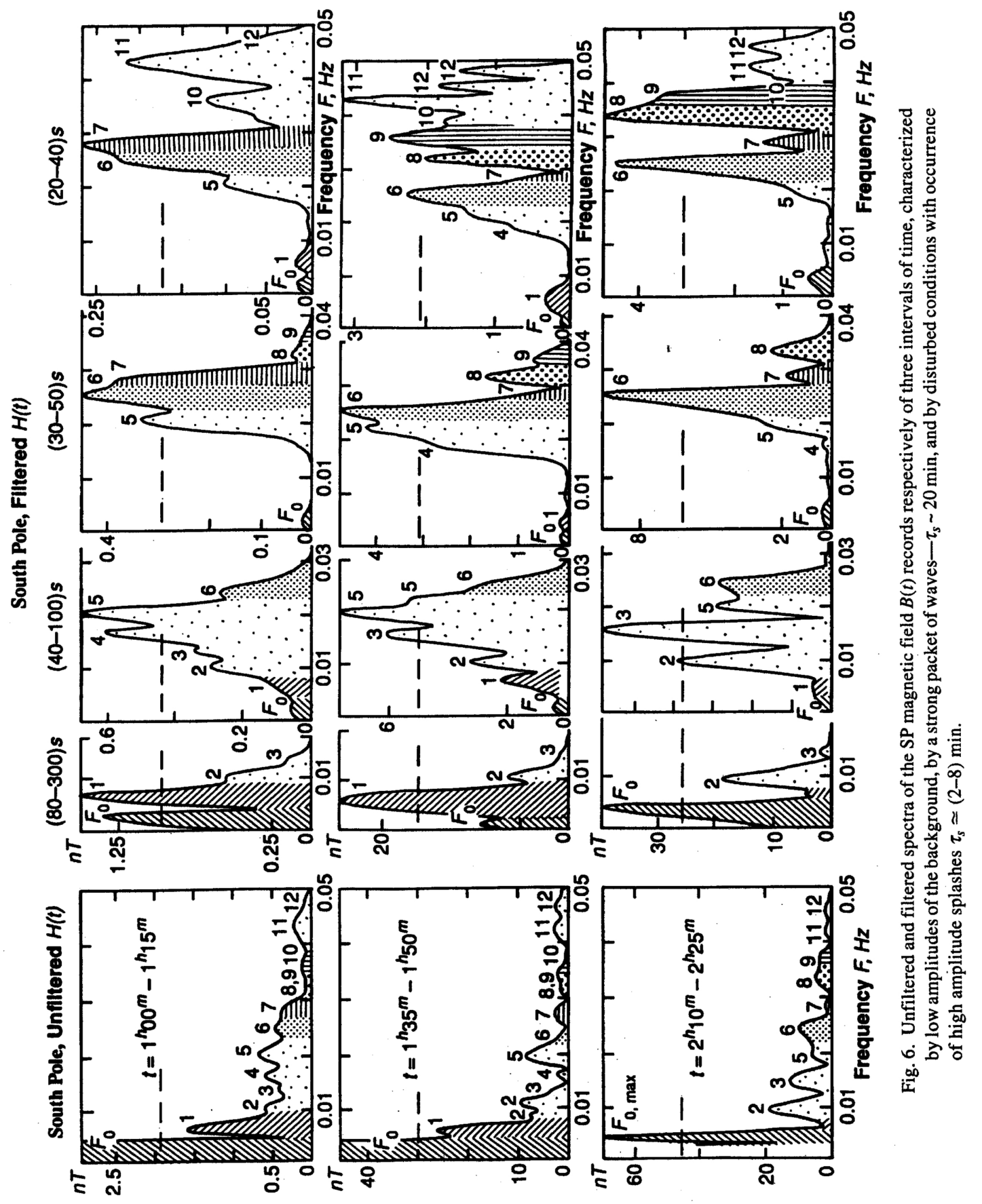




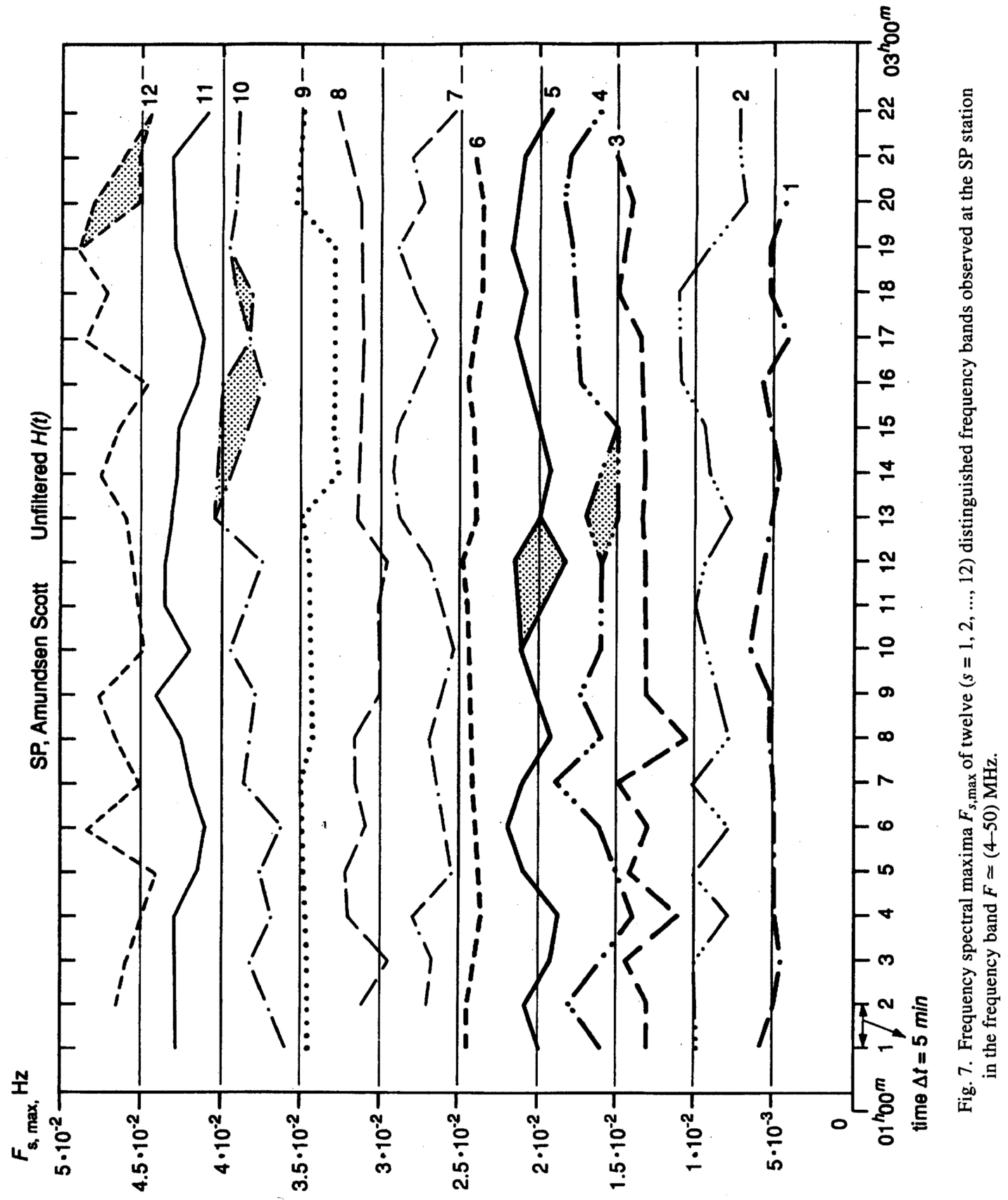




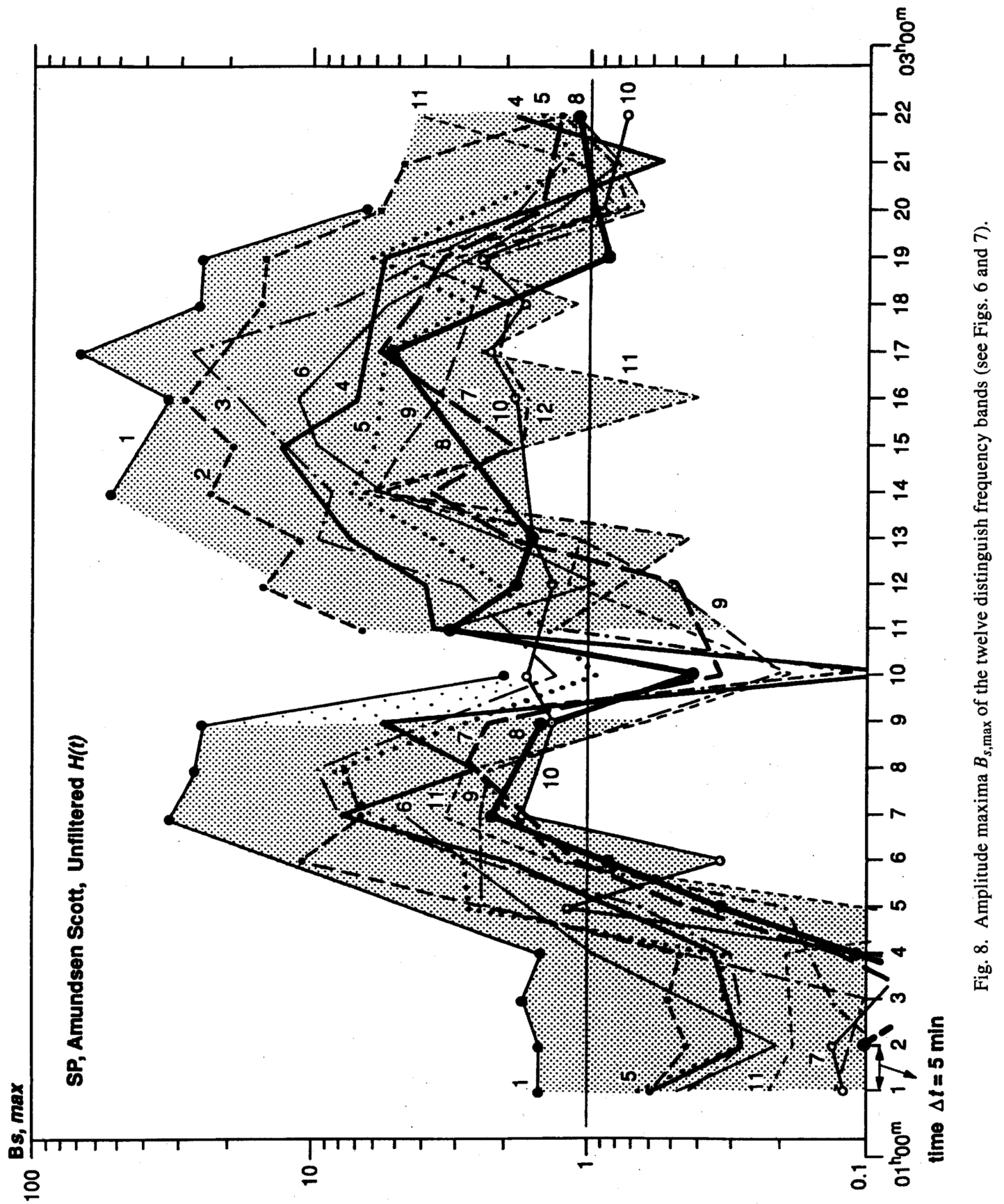


resonance frequencies of the magnetospheric cavity. However, the resolution of the spectra studied in those papers was insufficient to determine in more detail the spectral lines in the frequency range (2235) MHz.

- The mean frequencies $\overline{F_{s, \max }}$ are similar both during the quiet periods, when the amplitudes of these maxima on average varied in the interval $B_{s, \max } \simeq(0.1-1.5) \mathrm{nT}$, and during the disturbed periods, when $B_{s, \max } \simeq(2-40)$ nT (Fig. 6).

- The amplitudes of the maxima of the filtered oscillations shown in Fig. 6 are equal to, respectively, $B_{s, \max } \simeq(0.02-0.5) \mathrm{nT},(20-25) \mathrm{nT},(1.5-1.9) \mathrm{nT}$.

- The amplitudes of the different maxima $B_{s, \max }$ of the spectra change irregularly in time, and also have a dependence on their number $\langle s\rangle$. That is, the energy of different maxima is quite variable (Fig. 8). However, in general, the variations with time are reasonably similar. The maxima and minimum of $B_{s, \max }(t)$ appear at the same time periods. There is a large increase in amplitude of $B_{s, \max }$ between the time markers 6 and 9 ( 0130-0145 UT) and a general enhancement following time marker 12 (0200 UT).

We remark here that the determination and choice of the first maximum $F_{1, \max }$ requires a careful examination. This is because other maxima with $F_{0}<F_{1, \max }$ also appear in the spectra. Some results of a detailed analysis of the unfiltered spectra in the frequency band $0 \leq F_{0} \leq F_{1 \text {,max }}$ and also by examination of the filtered spectra, are given in Table 1, and Table A-II in Appendix. The values $F_{0, \max }<F_{1, \max }$ and the amplitudes of these maxima are found to change irregularly in time; they are very unstable. We believe that the $F_{0, \max }$ are the lowest maxima of the spectra of the envelopes of the packets of waves which are variable at different time intervals $\Delta t_{\mathrm{F}}=15 \mathrm{~min}$ (see Fig. 2).

In considering of the spectra of the filtered data, it should be noted that the windows of the digital filters are not of pure rectangular shape; they have "tails". Therefore the frequency bands of the filtered spectra are broader than they should be for filter bands $\Delta t_{\mathrm{F}}$ of a pure square signal. This means that the amplitudes $B_{s, \text { max }}$ outside of the theoretical window are not precise. However, the values $F_{s, \max }$ should be rather correct and they provide more information about the frequency composition of the packets of oscillation. This is seen from the example spectra for SP data filtered in four different frequency bands, shown in the four right-hand columns of Fig. 6. The peaks in these spectra that correspond to the spectral peaks in the unfiltered spectra are numbered correspondingly. For comparison, the frequencies of the peaks from the spectra of the filtered data and their amplitudes are listed in Table A-III, together with the frequencies and amplitudes of the unfiltered spectra. The agreement in frequency values is quite good.

The cause of these properties of the bands $F_{s, \max } B_{s, \max }$ and of their possible nature are discussed in the next section. Here we also show for illustration in Figs. 9 and 10 that the behavior of the magnetic field $B(t)$ and of its spectra at the northern conjugate point NP - Iqaluit is similar to that at SP. The frequencies

Table 1. The shape maxima $F_{0, \max }$ and the first resonance maxima $F_{1, \max }$ of the unfiltered $H(t)$ component, South Pole.

\begin{tabular}{|c|c|c|c|c|c|c|}
\hline Tir & $00-1^{15}$ & $1^{05}-1^{20}$ & $1^{10}-1^{25}$ & $1^{15}-1^{30}$ & $1^{20}-1^{35}$ & $1^{25}-1^{40}$ \\
\hline & 0 & 000489 & 0.00444 & 0.00467 & .00460 & \\
\hline & 3 & 00095 & & 3 & 79 & \\
\hline Time & $1^{30}-1^{45}$ & $1^{35}-1^{50}$ & $\overline{1^{40}-1^{55}}$ & $1^{45}-2^{00}$ & $\bar{~} 1^{50}-2^{05}$ & $\overline{1^{55}-2^{10}}$ \\
\hline$F_{1, \text { max }}, H z$ & 0.00511 & 0.00533 & 0.00533 & 0.00667 & & 0.00467 \\
\hline$F_{0, m}$ & 0.00143 & 0.00032 & 127 & & .00095 & 127 \\
\hline Time & $2^{00}-2^{15}$ & $2^{05}-2^{20}$ & $2^{10}-2^{25}$ & $2^{15}-2^{30}$ & $2^{20}-2^{35}$ & $2^{25}-2^{40}$ \\
\hline$F_{1, \max }, H z$ & 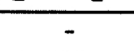 & 0.00467 & - & 0.00578 & & 0.00533 \\
\hline$F_{0, \max }, \mathrm{Hz}$ & 0.00095 & - & 0.00159 & 0.00032 & - & 0.00159 \\
\hline Time & $2^{30}-2^{45}$ & $2^{35}-2^{50}$ & $2^{40}-2^{55}$ & $2^{45}-3^{00}$ & \multirow{4}{*}{\multicolumn{2}{|c|}{$\begin{array}{c}F_{1, \max }=0.00520 \times \\
\times\left(1_{-0.11}^{+0.09}\right), H z \\
F_{0, \max }=0.00117 \times \\
\times\left(1_{-0.74}^{+0.36}\right), H z\end{array}$}} \\
\hline$F_{1, \max }, H z$ & 0.00533 & 0.00444 & 0.00667 & 0.00467 & & \\
\hline$F_{0, \text { max }}, H z$ & - & 0.00127 & - & 0.00159 & & \\
\hline & & & & & & \\
\hline
\end{tabular}



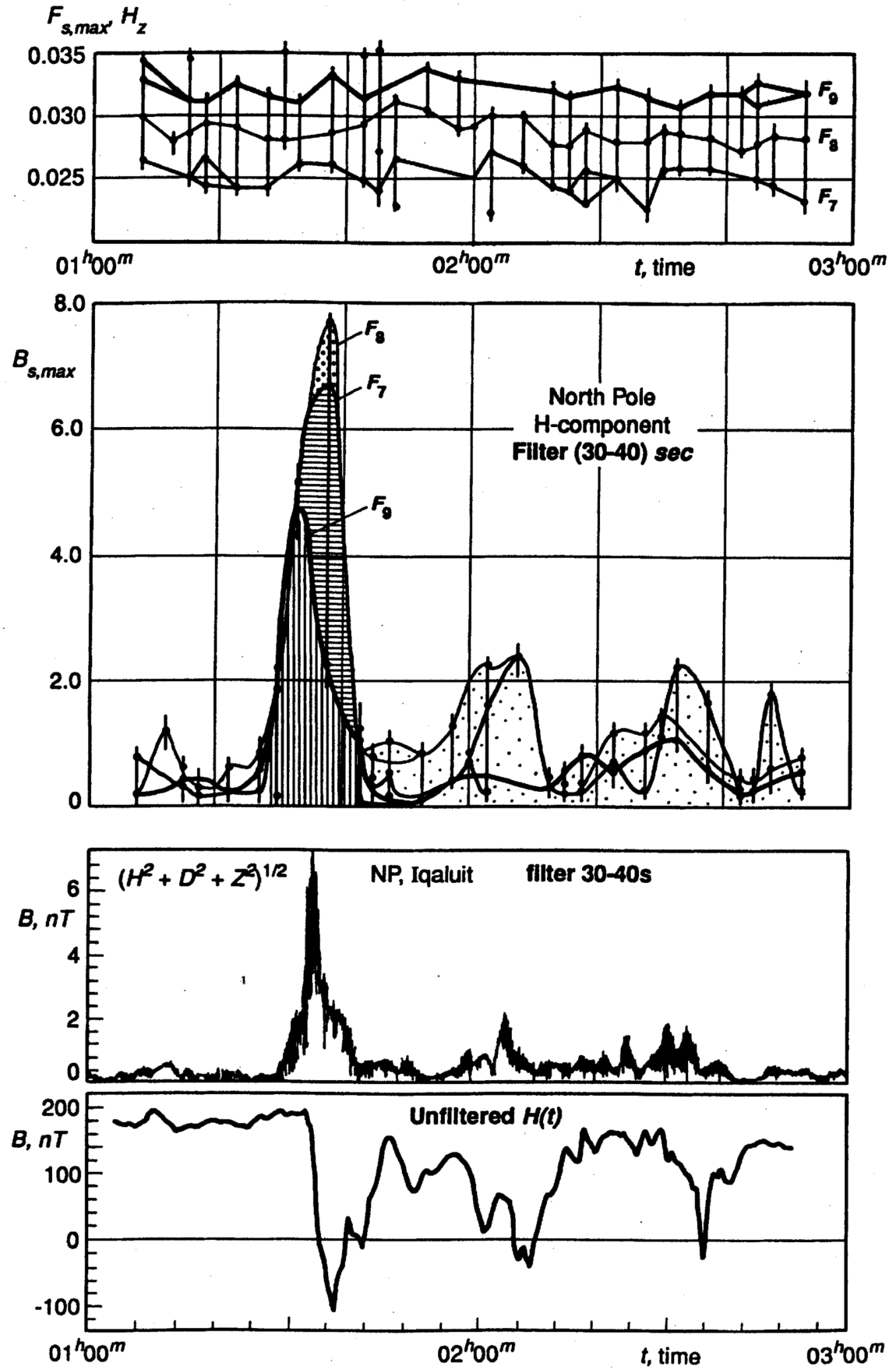

Fig. 9. Time dependencies of different characteristics of the $H(t)$ component of the magnetic field record, observed at NP station (see Figs. 2, 7, and 8). 


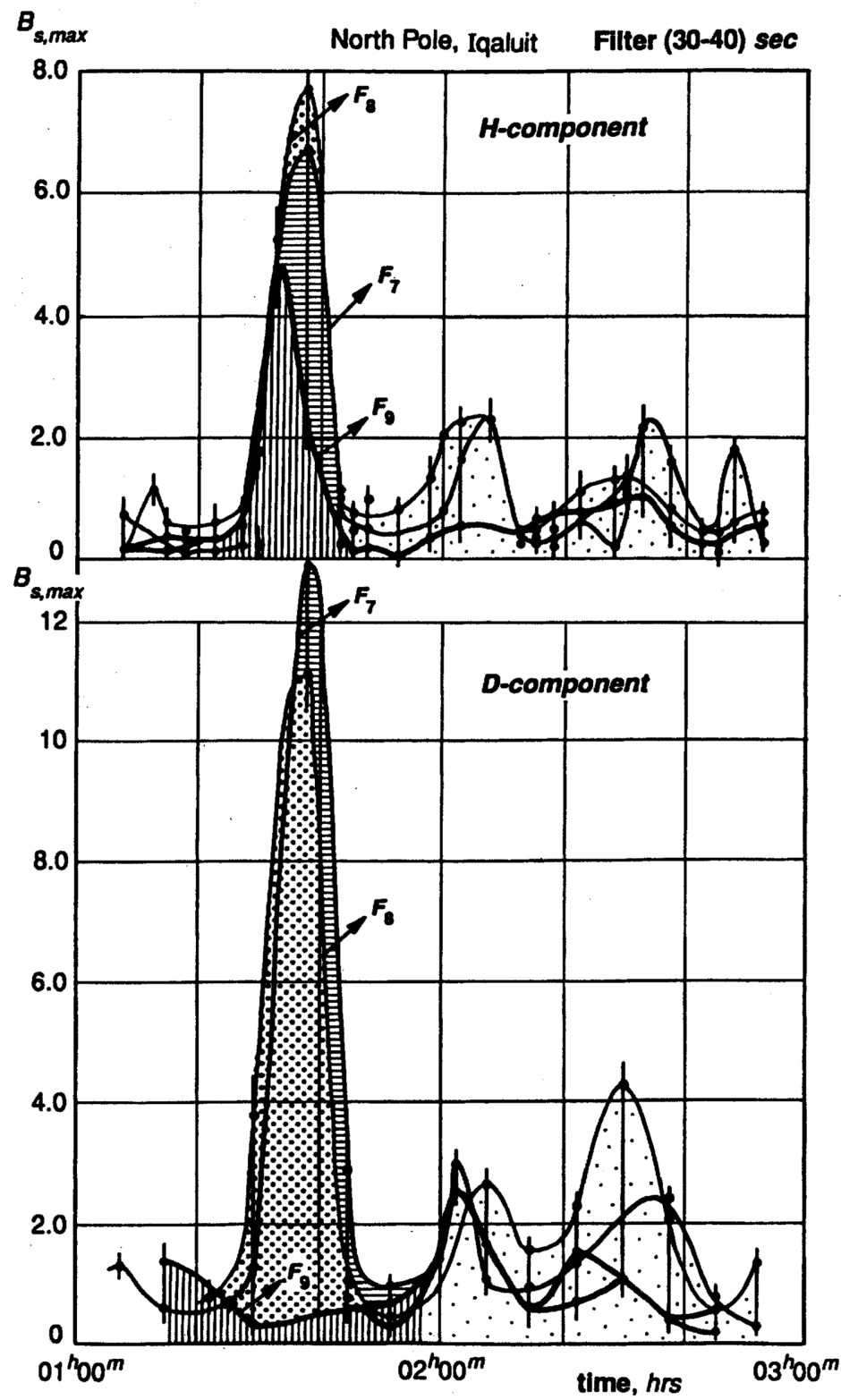

Fig. 10. Comparison of the time dependencies of $F_{s, \max }$ and $B_{s, \max }$ of the spectra of the $H(t)$ and $D(t)$ component records of the magnetic field, observed at the NP station.

noted, $F_{7}, F_{8}, F_{9}$, correspond to the mean frequencies as determined at SP (Table A-I). The similar behavior of the amplitudes of the spectral peaks of different components of $B(t)$ is also seen in Fig. 10 . The enhancement in power levels of the frequencies in this band corresponds to the overall enhancement of the moduli seen in the upper portion of Fig. 2. This is also seen from Table A-IV, where the values $F_{s, \max }$ and $B_{s, \max }$ of filtered data recorded at IQ (NP) and SP are compared. The amplitudes of these spectra are more regular and symmetrical than those of the SP station. This difference of the magnetic field variation at the IQ (NP) and the SP locations was noted above. 


\section{Eigenvalues (Resonance Oscillations) of the Magnetosphere}

The principal properties of the experimental data examined above, namely:

- the similarity of the time records of filtered magnetic field oscillations,

- the multiple line character of the spectra and the quantitative coincidence of the values of $F_{s, \max }$ in quiet and disturbed periods of the magnetosphere,

IQ (NP)

- the quantitative and qualitative similarity of the spectra obtained at SP and at the conjugate point

all indicate that the creation and the existence of these em. oscillations in the magnetosphere are of a common nature, and are therefore produced by a single mechanism.

We propose that the oscillations result from fundamental resonances, particularly of the magnetosphere as a whole or of some of its parts. This huge oscillating system has, as any body, a continuum degrees of freedom, $s=1,2, \cdots$. Twelve of them were identified in the frequency band analyzed in our data. These oscillations are characterized by the maximal frequencies of $F_{s, \text { res }}=F_{s \text {, max }}$. They exist continuously in the magnetosphere in the background plasma em. environment.

The background appeared to consist of two parts. One of these is similar to white noise. The second part is produced by the resonance oscillations. At some times, these oscillations are swinging/amplified so that strong, isolated packet of waves of different durations $\tau_{s}$, and bursts of oscillations $\tau<$ or $<<\tau_{s}$ are produced. This swinging of the background oscillations can be due to the excitation of the oscillation system by sudden disturbances. The sources of these disturbances can be the flow of the solar wind around the magnetosphere. Another source may be the gyro-resonance instability of the magnetoplasma, and perhaps also an internal dynamic effect such as changes in the neutral winds and in the plasma drift. These sources can support these oscillations by feeding additional energy into the oscillating system (see Alpert and Lanzerotti, 1998).

The variations of the relative ratios $\left(F_{s, \max } / F_{1, \max }\right)=\left(F_{s, \text { res }} / F_{1, \text { res }}\right)$ of the continuum of resonance frequencies is one of the basic characteristics of any oscillatory system of many degrees of freedom. Ratios of the mean values $\overline{F_{s, \max }}$ of these maxima (see Eq. (7)) obtained at the (NP and SP), and at the Tuckerton and Point Arena stations are respectively equal to

$$
\delta F_{s, \text { res }} \frac{\overline{F_{s, \text { res }}}}{\overline{F_{1, \text { res }}}}=\begin{aligned}
& 1.77,2.67,3.23,3.89,4.70,5.38,6.13,6.75,7.34,8.17,8.91, \\
& 1.70,2.45,3.34,3.81,4.50,5.20,6.65,6.57,7.44,8.22,8.78,
\end{aligned}
$$

(see the bold lines in Fig. 11 and Table A-I).

It is most instructive to note that these ratios are very close to the ratios of the spectral maxima of a rectangular-square signal, which are equal to

$$
\delta\left(F_{s, \max }\right)=1.72,2.43,3.13,3.83,4.53,5.26,5.93,6.63,7.33,8.03,8.73 .
$$

Of additional interest is the fact that the ratios of the Schumann resonances of the Earth's wave guide, which is a spherical wave guide with radii $R_{\text {out }}=\left(R_{0}+h\right)$ and $R_{0}$ when $h \ll<R_{0}(h=100 \mathrm{~km})$ are also similar and equal to

$$
\delta\left(F_{s, \mathrm{res}}\right)=1.73,2.44,3.16,3.87,4.59,5.30,6.00,6.72,7.42,8.13,8.83
$$

(see Alpert and Fligel, 1970) even though the Schumann resonance frequency values are considerably higher than the $F_{s, \max }$ given in Eq. (7). 
Plotted in Fig. 11 are the values of $F_{s, \max } / F_{s, 1}$ as a function of $(s=1,2, \ldots, 12)$ for the spectral determinations for different 15 minute time segments. While there is a spread in the ratios among the different intervals, they are also reasonably well clustered overall around the lines connecting the ratios for a square-wave signal and the Schumann resonances, which are also shown. The properties of the spectral maxima and of their resonance nature are discussed in a companion paper (number III) in more detail. However, here it is important to indicate one of their significant peculiarity.

The exchange of the energy between different orders of freedom - that is, the pumping of the energy from one resonance "circuit" to another-is a fundamental characteristic of any multi-resonance system. When one of the resonance-circuits of the system is excited, then, step-by-step, the other circuits are also excited. The character of this process, namely the relaxation time of generation of all these resonance oscillations and their amplitudes, depends on the character of the coupling between different orders of freedom. Also, the so called natural frequencies of the observed oscillations of such a system (see section 5 ), in our case the observed frequencies $F_{s, \max }=F_{s, \text { res }}$, are not equal to the normal frequencies $F_{s}$ of the system when it is not excited. Therefore, the values of $F_{s, \text { res }}$ depend on the behavior of the coupling/ pumping process.

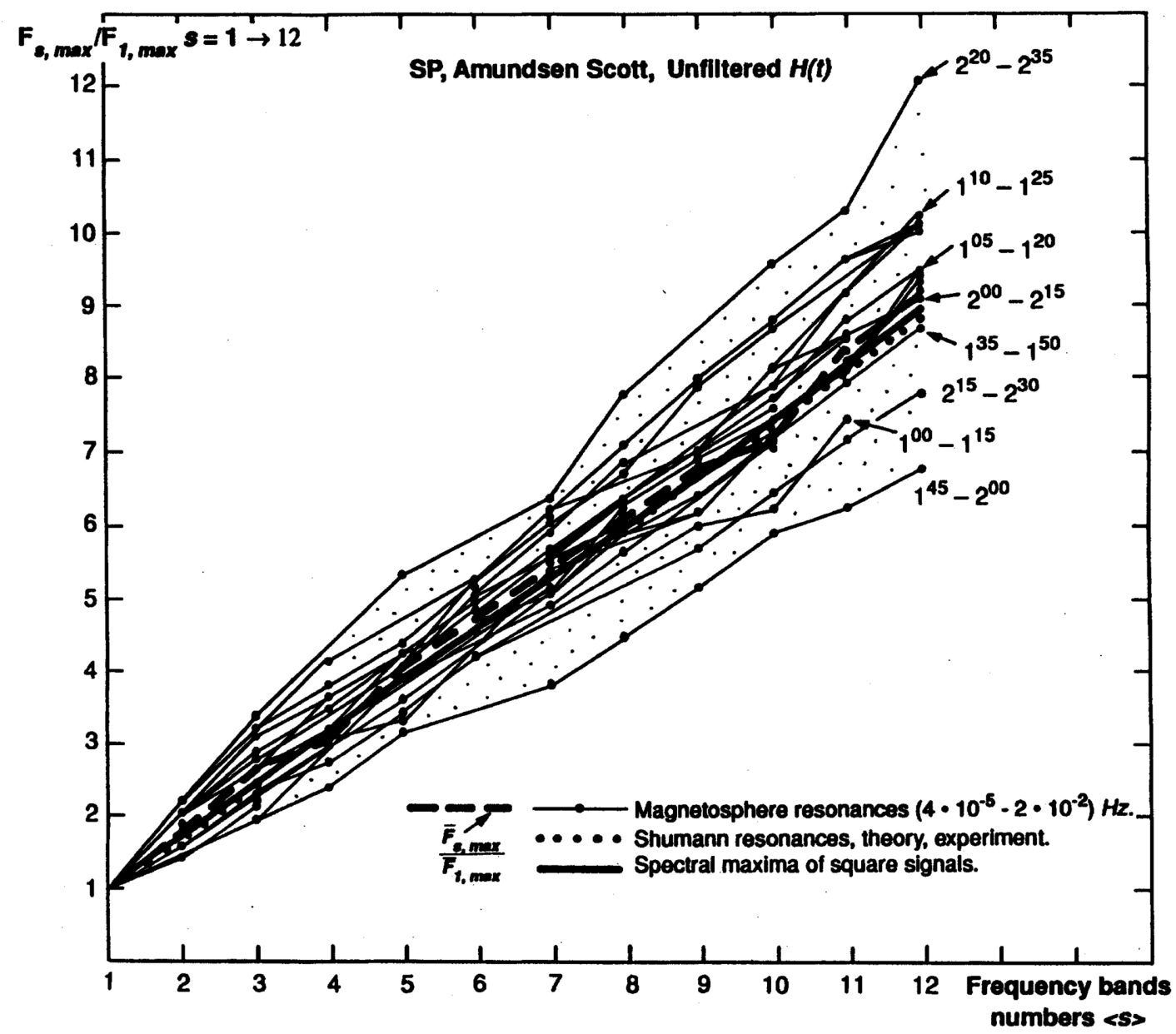

Fig. 11. Ratios of the frequency maxima $B_{s, \max } / B_{1, \max }, s=1,2, \ldots, 12$ of the distinguished 12 spectral frequency bands of the magnetic field records, observed at the SP station. The corresponding ratios of their mean values and of the Schumann resonances, and of the spectral maxima of a rectangular signal are also given. 

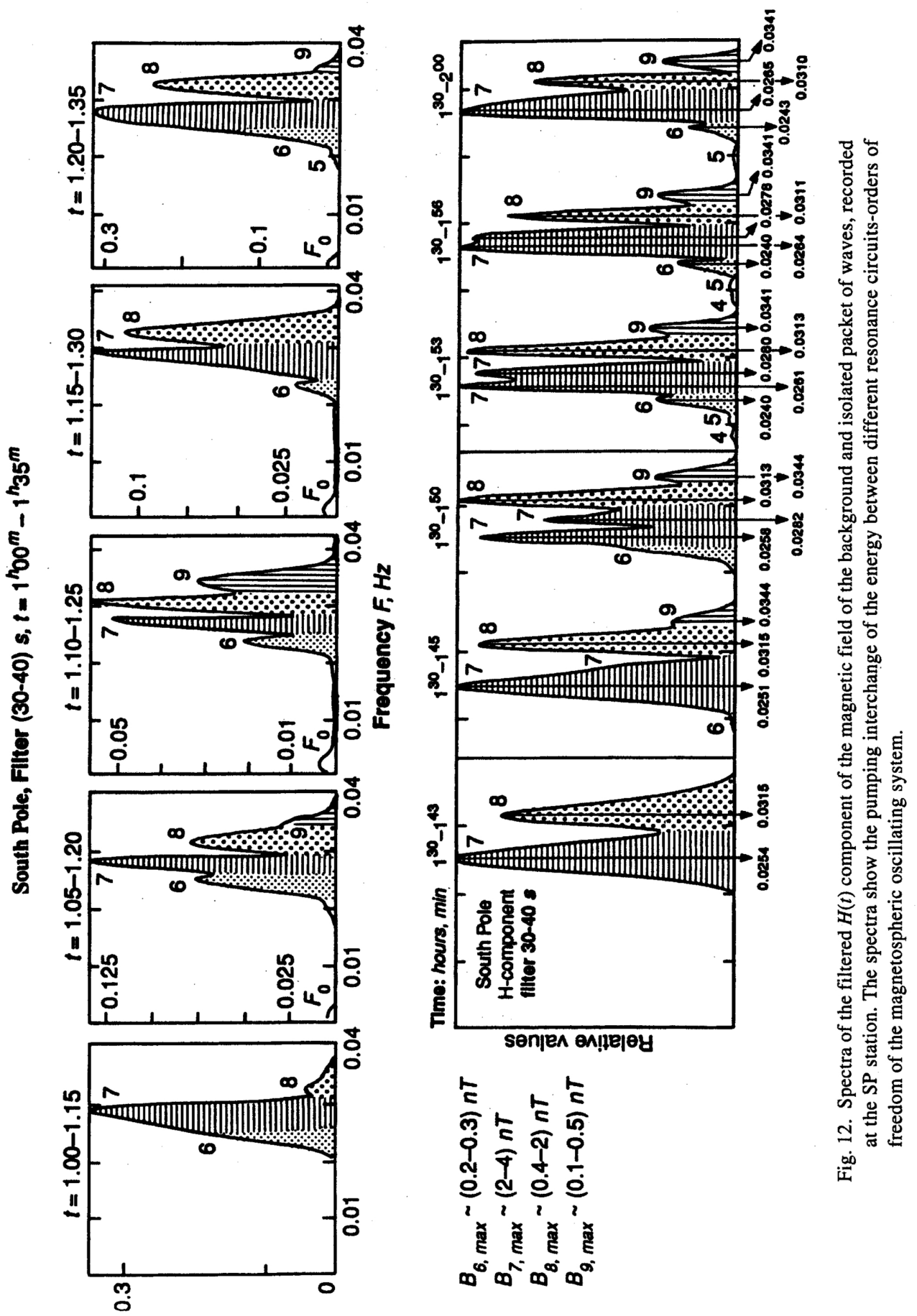
These phenomena, namely the possible pumping of energy from one order of freedom to another, are shown for illustration in Fig. 12. The top row of spectra in Fig. 12 corresponds to overlapping 15 minute segments during the interval of geomagnetic quiet (0100-0135 UT) when the amplitudes of the spectra of the background were small; $B_{s, \max }<$ or $<(0.1-0.3) \mathrm{nT}$. The second row of spectra corresponds to a sequence of spectra from time segments of increasing length during an interval of more magnetic activity $(0130-0200)$ UT. The amplitudes in this second row $B_{s, \max } \leq(2-4) \mathrm{nT}$ are related since the time intervals of successive spectra increase with increasing time.

The most stable maxima during both of the time intervals are the bands $F_{7, \max }$ and $F_{8, \max }$. The other bands $F_{6, \max }$ and $F_{9, \max }$ appear to be generated from these two and all grow and wane with time. For example, a small hump occurs on the low frequency side of $F_{7, \max }$ during the time interval 0100-0115. This subsequently develops into a distinguished $F_{6, \max }$ and then disappears again by the 0120-0135 UT interval. Note also that in the second set of spectra that a bifurcation of the $F_{7 \text {,max }}$ occurs. Such instances of bifurcation are also evidenced in Fig. 6. Perhaps bifurcation is connected with large-scale plasma clouds formations and their movement through the plasma regions where the oscillations are created. This changes the structure of the oscillating system and can produce an additional order of freedom in the appropriate frequency region. Another possible cause of this bifurcation can be the variation in time of the gyro-resonance frequencies of different frequency bands. Therefore, some $F_{s, \text { res }}$ bands can become more enhanced. The noted phenomena can be the cause of the complicated irregular character of the behavior of the amplitudes $B_{s, \max }$ of the spectra.

\section{Brief Theoretical Remarks}

After concluding that the sequence of the unfiltered $F_{s, \max }$ of the spectra can be fundamental resonance frequencies of the magnetosphere em. environment, we examined spectra of the sequential 15 min records of the unfiltered magnetic field $B(t)$. To this end, we calculated spectra of such signals with envelopes similar to the shape of the envelopes of these records. Results of these calculations and the properties of the estimated resonance frequencies of the magnetosphere $F_{s, \max }=F_{s \text {,res }}$ (see Eq. (7)) are given in Alpert et al. (1997). However, it is perhaps in place here to make the following simple remarks.

a. The oscillations of a linear system of many orders of freedom, of the magnetosphere in our case, can be described by the well known Lagrange equations of motion expressed in generalized coordinates $q_{s}$ and $\dot{q}_{s}$, namely by

$$
\frac{d}{d t}\left(\frac{\partial T}{\partial \dot{q}_{s}}\right)+\frac{\partial U}{\partial q_{s}}=0
$$

where $s=1,2, \ldots$ (see, for example, Mandelshtam, 1955). In our case, the generalized coordinates are

$$
q_{s}=B_{s}, \quad \dot{q}_{s}=\dot{B}_{s},
$$

here $B_{s}$ and $\dot{B}_{s}$ are the amplitudes $B_{s}(t)$ and the time derivatives $\dot{B}_{s}=\partial B / \partial t$ of the magnetic field of the $\langle s\rangle$ bands. The variables of the Lagrange equations $T$ and $U$ are respectively the kinetic and potential energy of the oscillatory system. For example, in a system of two orders of freedom $(s=1$ and 2$)$,

$$
T=a_{11} \dot{q}_{1}^{2}+2 a_{12} \dot{q}_{1} \dot{q}_{2}+a_{22} \dot{q}_{2}^{2}, \quad U=b_{11} q_{1}^{2}+2 b_{12} q_{1} q_{2}+b_{22} q_{2}^{2}
$$

In these equations $\dot{q}_{1} \dot{q}_{2}$ and $q_{1} q_{2}$ and their coefficients $a_{12}$ and $b_{12}$ determine the character of the coupling of the two oscillatory degrees of freedom. For example, in Eq. (13) the coupling coefficient $a_{12}$ of a mechanical system is of an inertial nature, and in a electrical system the coupling is of an inductive nature. 
In the equation for $U$, in the two cases, the coupling coefficients are of a different nature. The magnetosphere as a whole, as well as portions of it, can certainly not be considered as a rigid body. In rigid bodies the degrees of freedom are rigidly connected. The magnetospheric cavity is, generally speaking, a soft body. Therefore, in our system the connection between different degrees of freedom is regulated by some type of soft coupling. In such systems the pumping (that is the interchange of the energy of oscillations between different orders of freedom) should be very noticeable. This was illustrated in Fig. 11 for two sets of Fourier spectra.

The determination of the coupling coefficients $a_{1,2}, a_{2,3}, \ldots, b_{1,2}, b_{2,3}$, etc. would be one of the most important and difficult tasks of this problem. The theoretical, mathematical approach to this is complicated in our case, and the formulations of these theoretical problems can be done only on the basis of extensive experimental data.

We also note here that the solution of the Lagrange equations can be reduced to the solution of a system of differential equations:

$$
\left(a_{11} \ddot{q}_{1}+b_{11} q_{1}\right)+\left(a_{12} \ddot{q}_{2}+b_{12} q_{2}\right)=0,\left(a_{12} \ddot{q}_{1}+b_{12} q_{1}\right)+\left(a_{22} \ddot{q}_{2}+b_{22} q_{2}\right)=0
$$

If

$$
q_{1} \simeq c_{1} \cos (2 \pi F t+\alpha), \quad q_{2} \simeq c_{1} \cdot c_{2} \cos (2 \pi F t+\alpha),
$$

where the values $c_{1}, c_{2}, F$, and $\alpha$ are considered as constants. Then the normal angular frequencies $2 \pi F$ $=\omega$ (i.e. the resonance frequencies $F_{s, \max }$ ) of these oscillations can be determined by

$$
\begin{aligned}
& \left|\begin{array}{ll}
\left(a_{11} \omega^{2}-b_{11}\right) & \left(a_{22} \omega^{2}-b_{12}\right) \\
\left(a_{12} \omega^{2}-b_{12}\right) & \left(a_{22} \omega^{2}-b_{22}\right)
\end{array}\right|=0, \\
& \left(a_{11} a_{22}-a_{12}^{2}\right) \omega^{4}-\left(a_{11} b_{22}+b_{11} a_{22}+2 a_{12} b_{12}\right) \omega^{2}+\left(b_{11} b_{22}-b_{12}^{2}\right)=0 .
\end{aligned}
$$

The partial frequencies of this system $\omega_{1} *=2 \pi F_{1} *$ and $\omega_{2} *=2 \pi F_{2} *$ are estimated when the coupling coefficients $a_{12}=0$ and $b_{12}=0$. Then it follows from Eq. (17) that

$$
\omega_{1}^{*}=\frac{b_{11}}{a_{11}}, \quad \omega_{2}^{* 2}=\frac{b_{22}}{a_{22}}
$$

It is easy to show that

$$
\omega_{1}^{2}<\omega_{1}^{* 2}<\omega_{2}^{* 2}<\omega_{2}^{2} .
$$

Equation (18) and the condition (19) show that the variability of the resonance (normal) frequencies $F_{s, \max }$ $=F_{s \text {,res }}$ depends on the character of the process of interaction between different resonance circuits-orders of freedom. Certainly these frequencies and the partial frequencies of the oscillating system $F_{s, \max }^{*}$ are also variable due to variation of the parameters of the magnetoplasma.

b. The resonance amplification/swinging of the background, which consists of $\langle s\rangle$ narrow bands of oscillations, may be simulated by 


$$
Y(t)=\sum_{s}\left[b_{s} \cdot \sin \left(2 \pi F_{s, \max } \cdot t\right)\right]_{t=\left(0 \rightarrow t_{0}\right)}+\sum_{s}\left[\frac{b_{s} \cdot \sin \left(2 \pi F_{s} \cdot t\right)}{a_{0}^{2} \cdot \sqrt{\left(t^{2}-t_{\mathrm{res}}^{2}\right)^{2}+Q^{2}}}\right]_{t=\left(t_{0} \rightarrow t_{\text {end }}\right)}
$$

The first term of Eq. (20) is the sum of $s$ bands of the background oscillations before the beginning of the resonance process, at $t \leq t_{0}$. The second term describes the resonance swinging of these oscillations during the time $t=t_{0} \rightarrow t_{\text {end }}$. This term includes a resonance function

$$
\psi=\left(a_{0}^{2} \cdot \sqrt{\left(t^{2}-t_{\mathrm{res}}^{2}\right)^{2}+Q^{2}}\right)^{-1}
$$

The meaning of the resonance function $\psi(. .$.$) is the following. During the time t=t_{0} \rightarrow t_{\mathrm{end}}$, the combination of the parameters of the local region of the magnetosphere (of the wave source, which determines its resonance frequency $F_{\text {res }}$ (see Eqs. (1) and (2))) becomes close, or even equal, to one of the frequencies $F_{s, \max }$ of the background oscillations. The close approach of $F_{s}$ to $F_{\text {res }}$ occurs at $t=t_{\text {res. }}$. At $t$ $=t_{\text {end }}$ this resonance condition disappears, and the value $F_{\text {res }}$ differs again substantially from the background frequencies. In Eq. (20) $a_{0}^{2}=1 \mathrm{sec}^{-2}$ is a dimensional multiplier, and $Q=(t / \delta) \mathrm{sec}^{2}, \delta \mathrm{sec}^{-1}$ characterize the attenuation of the resonance system. We note here that the resonance function of any oscillating mechanical or electric current system with a resonance frequency $F_{0}$ is equal to $\left(\sqrt{\left[F_{0}^{2}-F(t)^{2}\right]+4 F(t)^{2} \delta^{2}}\right)^{-1}$, where $F(t)$ is the frequency of the external source, which is proportional to $\cos (2 \pi F \cdot t)$.

With the help of Eq. (20) the oscillations of the $H(t)$ component (the packet of waves shown in Fig. 3 ) was simulated taking into account only two constituents $F_{1, \max }$ and $F_{2, \max }$ of these packets of waves. A rather close agreement with the experimental data can be achieved. We also studied the evolution of the shape of the envelopes of packets of waves $Y(t)$ depending on the magnitudes of the ratios $\alpha=F_{1} / F_{2}$. These calculations show that depending on $\langle\alpha\rangle$, the shape of the packet of oscillations $Y(t)$ can differ considerably and also illustrate the variety and sometimes curious envelope shapes of the frequently observed experimental packets of waves (see Alpert et al., 1997).

\section{Summary and Conclusions}

The results of our study presented above have shown:

Firstly, that there is a sufficiently good synchronous behavior of the envelopes of the amplitudes of the filtered magnetic field oscillations in the entire frequency band $F \simeq(0.7-50) \mathrm{mHz}$ (see Figs. 4 and 5). These oscillations include several bands that are often distinguished by different nomenclature; e.g. Pc2, Pc3, Pc4, Pc5. The physical basis for distinguishing between these designations has never been very clear in the literature or to most researchers in the field; the designations are often just a convenient short hand way of designating a frequency band of interest.

Secondly, that the amplified packets of waves arise from the "background" oscillations that have similar spectral characteristics both in quite and disturbed periods of time. These and some other features of the observed data led us to the following conclusions.

- The em. packets of waves observed in the magnetosphere can be considered as resonance oscillations of a continuum of degrees of freedom of the magnetosphere system or of some of its portions. We found 12 resonance frequencies - eigenvalues of this system. With such a conclusion there is likely to be little physical reason to use the nomenclature of several different Pc pulsations bands. 
- These oscillations exist continuously in the magnetosphere and are the main part of its em. background during, quiet electromagnetic conditions of the magnetoplasma media.

- Under appropriate conditions these oscillations are swinging/amplified, and strong isolated packets of waves are formed. During such disturbed periods of time even stronger short bursts of oscillations are also produced.

- The spectral characteristics of these em. waves, both in the quiet and disturb period of time, are similar.

- Examination of the modulation envelopes of different frequency bands indicates that there are short intervals of time when individual frequencies may be enhanced compared to adjacent bands. The sources of these events require further identification.

- The stability in the $F_{s, \text { res }}$ frequencies identified, and the close match in the frequency ratios $F_{s, \max } / F_{1, \max }$ to those calculated from the Fourier analysis of a square wave signal, suggest that the sources of the resonances can arise from sudden changes in magnetosphere plasma conditions.

- The observed pumping/interchange of the energy between different frequency bands strengthens our main conclusion that a system of resonance "circuits" of a magnetospheric oscillating system is observed in the experimental data examined.

We have to note again* that only the results of examination of data obtained at high latitudes during two hours of a night time geomagnetic disturbance are presented in detail in the paper. At the local time studied, the two conjugate stations that are used in the analysis are in the polar cap magnetosphere. The similarity of the responses at these two NP and SP stations, and also at the middle latitude Tuckerton and Point Arena stations indicate that the conclusions reached are more global in nature. However, further detailed treatment of experimental data, obtained under different conditions at different observation locations, at different latitudes and local times, is needed. It is also very important to extend this work by means of data obtained in situ on satellites. Such data are needed for better investigation and understanding of the characteristics and origin of this huge oscillating system. The theoretical, mathematical approach to this manifold complex problem is possible through the self consistent study and solution of the kinetic, Poisson and Lagrange equations. But even the formulations of these theoretical problems can and should be based on manifold careful examination of results of different kind of experimental observations.

We are very grateful to Svetlana Alpert for her assistance in the preparing this paper and for laborious computer calculations. A portion of the work by Ya. Alpert was supported by NSF grant DPP89-21094.

\section{APPENDIX}

Tables A-I to A-IV given in Appendix include detailed information about the Fourier spectra of the unfiltered magnetic field $B(t)$ and of the filtered oscillations.

All the spectra were calculated by steps $\Delta F_{s}=2.222 \ldots \cdot 10^{-4} \mathrm{~Hz}$. To have high resolution spectra, 360 zeros were added to the 90 initial data of the time records. They were done for time intervals $\Delta t_{\mathrm{F}}=15 \mathrm{~min}$. To examine in time their evolution, overlapped spectra were calculated for time intervals $\Delta t=5 \mathrm{~min}$. Namely 22 spectra were calculated for each case in the 2 hours observation period.

The notations used in the tables of the frequency spectra maxima $F_{s, \max }$ are the same as the notations $F_{s, \text { res. }}$ These frequencies can be considered as resonance frequencies because they can be eigenvalues of huge oscillating systems produced in the magnetosphere. In general, some hundreds of spectra were examined. 


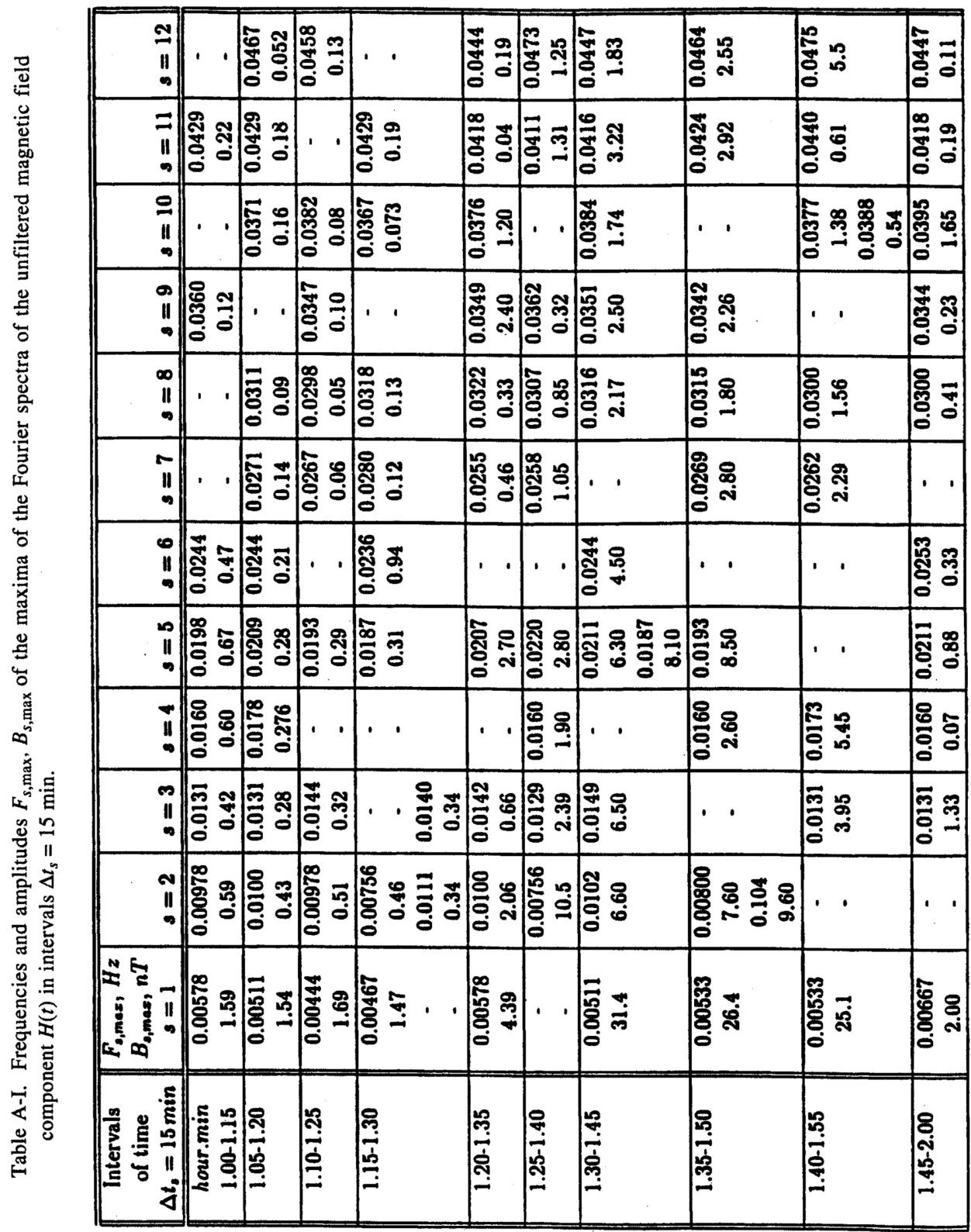




\begin{tabular}{|c|c|c|c|c|c|c|c|c|}
\hline $\begin{array}{c}9 \\
11 \\
\infty \\
\end{array}$ & $\cdot 1$ & 1 & 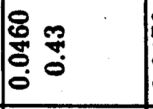 & 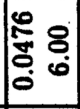 & : & 实 & 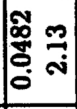 & F్ \\
\hline $\begin{array}{l}7 \\
11 \\
0\end{array}$ & 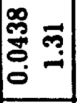 & 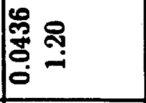 & 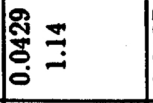 & 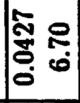 & 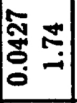 & 象 & E. & 急 \\
\hline $\begin{array}{c}9 \\
11 \\
0\end{array}$ & & 趈 & 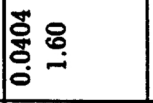 & . . & . . & శ్ & 总 & 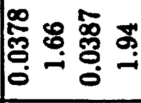 \\
\hline $\begin{array}{l}0 \\
11 \\
\infty\end{array}$ & & 晜 & 㱐 & 1 & $\cdot$. & . & $\cdot \cdot$ & . . \\
\hline $\begin{array}{l}\infty \\
\text { II } \\
\infty\end{array}$ & 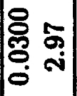 & 趈 & 苂 & స్స్ & $\begin{array}{ll}\bar{m} & : \\
0 & \infty \\
0 & :\end{array}$ & 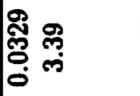 & 局 & 1. \\
\hline "ี & & 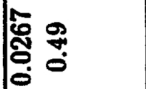 & 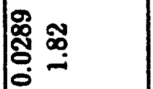 & 虑 & 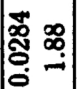 & 1. & · & 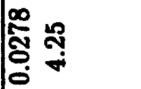 \\
\hline il & 焉 & 勇 & 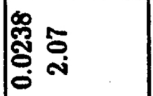 & ₹్: & ₹̛: & 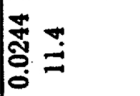 & 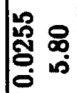 & 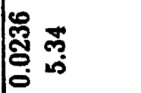 \\
\hline $\begin{array}{l}n \\
11 \\
\infty\end{array}$ & & 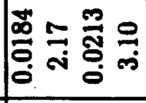 & 兽 & 홍 옹 & $\mid \begin{array}{ll}\infty & 0 \\
0 & 0 \\
0 & 0 \\
0 & 0 \\
\end{array}$ & . . & స్ & 恿 \\
\hline II & 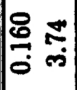 & 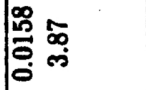 & م. &. & . . & 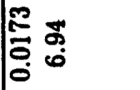 & . . & . . \\
\hline $\begin{array}{l}\infty \\
11 \\
0\end{array}$ & & 离 & 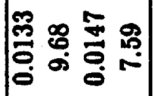 & $\underset{0}{p}$ & 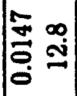 & . . & 冚 & 悉 \\
\hline$\underset{n}{N}$ & $\mid \begin{array}{ll}\infty & \\
0 & 0 \\
0 & 0 \\
0 & 0 \\
0 & 0 \\
0 & 0\end{array}$ & 第 & 品 & 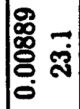 & 局 & 总 & & 是 \\
\hline 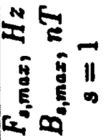 & & 隐 & ' . & क्षें & 蕞 & 密 & ' & 䜸 \\
\hline$\frac{11}{40}$ & 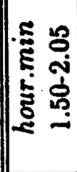 & 角 & 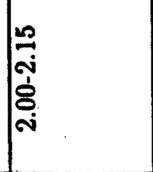 & 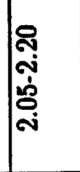 & 令 & 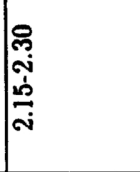 & 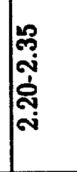 & 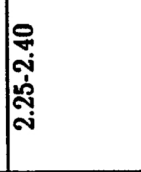 \\
\hline
\end{tabular}




\begin{tabular}{|c|c|c|c|c|c|c|c|c|}
\hline $\begin{array}{l}\text { N } \\
\text { II }\end{array}$ & 要 & 要 & 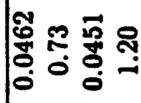 & 葡 & 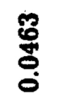 & $\underset{\infty}{\vec{\sigma}}$ & $\underset{\infty}{\mathscr{\infty}}$ & $\begin{array}{l}\infty \\
\infty \\
\infty\end{array}$ \\
\hline च & 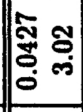 & స్త్ & 䇰웅 & : & 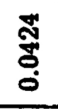 & $\underset{\infty}{\mp}$ & $\underset{\infty}{\mathscr{\infty}}$ & $\underset{\infty}{\infty}$ \\
\hline $\begin{array}{c}0 \\
11 \\
5\end{array}$ & 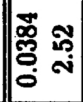 & 战 & 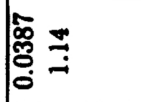 & 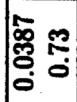 & $\begin{array}{l}\overrightarrow{0} \\
\stackrel{0}{o g} \\
0\end{array}$ & $\underset{\sim}{\stackrel{D}{~}}$ & $\underset{\sim}{\mathscr{\rho}}$ & $\underset{\sim}{\text { พั }}$ \\
\hline $\begin{array}{l}0 \\
11 \\
\infty\end{array}$ & . . & 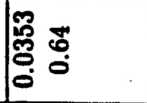 & 㺃 & 㟒 & $\begin{array}{l}\text { \%్ } \\
\text { ơ } \\
0\end{array}$ & $\underset{\substack{2 \\
0}}{2}$ & ஜூ & $\underset{0}{\mathfrak{T}}$ \\
\hline $\begin{array}{l}\infty \\
11 \\
0\end{array}$ & 茼 & 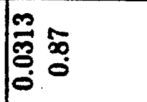 & 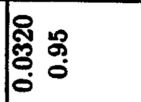 & 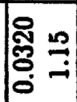 & $\begin{array}{l}\stackrel{0}{*} \\
\stackrel{0}{0}\end{array}$ & $\underset{0}{\infty}$ & ஜூ & ర్. \\
\hline רI & 兽 & :̊: & 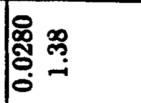 & & 总 & 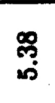 & 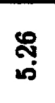 & 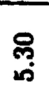 \\
\hline $\begin{array}{l}0 \\
11 \\
0\end{array}$ & . ' & 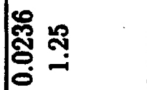 & 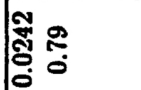 & 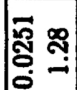 & ఫ্: & $\stackrel{R}{?}$ & קึ & : \\
\hline $\begin{array}{l}0 \\
11 \\
0\end{array}$ & 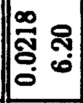 & · . & 옳 & 桷 & ণั: & $\underset{\substack{\mathscr{D} \\
\text { g }}}{\mathbb{D}}$ & $\underset{\substack{\infty \\
\text { ஜj }}}{\mathscr{\infty}}$ & $\underset{\infty}{\infty}$ \\
\hline iI & 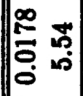 & | & 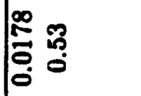 & 趈 & $\stackrel{8}{\circ}$ & ભึֶ & $\stackrel{m}{\oplus}$ & $\frac{0}{\infty}$ \\
\hline $\begin{array}{c}\infty \\
11 \\
\infty\end{array}$ & & 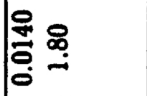 & 预 & . & 旁 & $\stackrel{5}{\text { ஸे }}$ & $\underset{\text { H }}{\text { S }}$ & $\underset{\text { J }}{J}$ \\
\hline $\begin{array}{c}N \\
11 \\
\infty\end{array}$ & 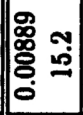 & 战 & 토융 & $\vec{Z}$ & 둥 & F & 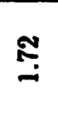 & $\stackrel{乛}{2}$ \\
\hline 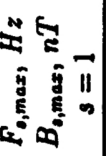 & 触 & 志 & . & 象 & 藏 & 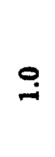 & 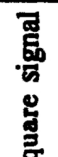 & 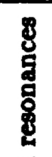 \\
\hline 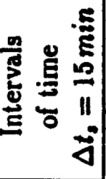 & 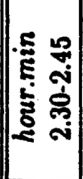 & 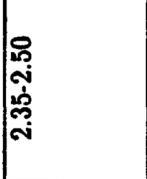 & | & 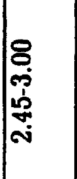 & $\left.\right|_{2}$ & 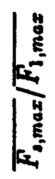 & 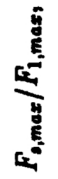 & E \\
\hline
\end{tabular}


Table A-II. The smallest maxima $F_{0, \max }$, and the first resonance maxima $F_{1, \text { res }}, F_{2, \text { res, }}$ and $F_{3, \text { res }}$ of the spectra, South Pole $(L=$ 13).

\begin{tabular}{|c|c|c|c|c|c|c|c|c|}
\hline Time $h r: \min$ & \multicolumn{4}{|c|}{$1: 00-1: 15$} & \multicolumn{4}{|c|}{$1: 05-1: 20$} \\
\hline Filter $\quad F, \mathrm{~Hz}$ & $F_{0, \text { max }}$ & $F_{1, \text { max }}$ & $\overline{F_{2, \max }}$ & $F_{3, \max }$ & $\overline{F_{0, \max }}$ & $\overline{F_{1, \max }}$ & $F_{2, \max }$ & $\overline{F_{3, \max }}$ \\
\hline $\begin{array}{cc}\text { Unfiltered. } & \mathrm{Hz} \\
n T\end{array}$ & $\begin{array}{c}0.00143 \\
14.30\end{array}$ & $\begin{array}{c}0.00578 \\
1.59 \\
\end{array}$ & $\begin{array}{c}0.00978 \\
0.59 \\
\end{array}$ & $\begin{array}{c}0.0131 \\
0.42 \\
\end{array}$ & $\begin{array}{c}0.00095 \\
9.33 \\
\end{array}$ & $\begin{array}{c}0.00489 \\
1.54 \\
\end{array}$ & $\begin{array}{c}0.0100 \\
0.43\end{array}$ & $\begin{array}{c}0.0131 \\
0.28\end{array}$ \\
\hline$(20-40) s \quad H z$ & 0.00200 & 0.00578 & - & 0.0129 & 0.00044 & 0.00511 & - & 0.0137 \\
\hline$(30-50) s \quad H z$ & 0.00200 & 0.00578 & 0.0102 & 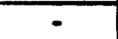 & 0.00067 & 0.00422 & 0.0100 & - \\
\hline $\begin{array}{r}(40-100) s \mathrm{~Hz} \\
n T\end{array}$ & 0.00222 & 0.00667 & $\begin{array}{c}0.0102 \\
0.294 \\
\end{array}$ & $\begin{array}{l}0.0131 \\
0.386 \\
\end{array}$ & 0.00067 & - & $\begin{array}{c}0.0102 \\
0.222 \\
\end{array}$ & $\begin{array}{c}0.0131 \\
0.244 \\
\end{array}$ \\
\hline $\begin{array}{r}(80-300) s \mathrm{~Hz} \\
n T \\
\end{array}$ & 0.00200 & \begin{tabular}{|c|}
0.00578 \\
1.50 \\
\end{tabular} & $\begin{array}{c}0.00956 \\
0.554\end{array}$ & - & 0.00044 & $\begin{array}{c}0.00511 \\
1.25 \\
\end{array}$ & $\begin{array}{c}0.0102 \\
0.40\end{array}$ & - \\
\hline Time $h r: \min$ & \multicolumn{4}{|c|}{$1: 10-1: 25$} & \multicolumn{4}{|c|}{$1: 15-1: 30$} \\
\hline \begin{tabular}{cc|} 
Unfiltered. & $H z$ \\
$n T$
\end{tabular} & $\begin{array}{c}0.00159 \\
6.58\end{array}$ & $\begin{array}{c}0.00444 \\
1.69\end{array}$ & $\begin{array}{c}0.00978 \\
0.516\end{array}$ & $\begin{array}{c}0.0144 \\
0.321\end{array}$ & $\begin{array}{c}0.00143 \\
6.93\end{array}$ & $\begin{array}{c}0.00467 \\
1.47\end{array}$ & $\begin{array}{c}0.00756 \\
0.457 \\
0.0111 \\
0.336\end{array}$ & $\begin{array}{c}0.0140 \\
0.338\end{array}$ \\
\hline$(20-40) s \quad H z$ & 0.00267 & - & - & - & 0.00111 & 0.00400 & 0.00756 & 0.0138 \\
\hline$(30-50) s \quad H z$ & 0.00244 & - & 0.0102 & - & 0.00133 & 0.00467 & 0.0109 & 0.0144 \\
\hline $\begin{array}{r}(40-100) s \mathrm{~Hz} \\
n T\end{array}$ & 0.00244 & - & $\begin{array}{l}0.0100 \\
0.248\end{array}$ & $\begin{array}{c}0.0144 \\
0.296\end{array}$ & 0.0133 & 0.0444 & $\begin{array}{c}0.00756 \\
0.094 \\
0.0109 \\
0.213\end{array}$ & $\begin{array}{c}0.0140 \\
0.322\end{array}$ \\
\hline $\begin{array}{r}(80-300) s \mathrm{~Hz} \\
n T\end{array}$ & 0.00244 & - & $\begin{array}{c}0.00978 \\
0.481\end{array}$ & 0.0144 & $\begin{array}{c}0.00111 \\
1.02\end{array}$ & $\begin{array}{c}0.00400 \\
1.22\end{array}$ & $\begin{array}{c}0.00756 \\
0.472 \\
0.0111 \\
0.288 \\
\end{array}$ & 0.0138 \\
\hline Time $h r: \min$ & \multicolumn{4}{|c|}{$1: 20-1: 35$} & \multicolumn{4}{|c|}{$1: 25-1: 40$} \\
\hline $\begin{array}{r}\text { Unfiltered. } \begin{aligned} H z \\
n T\end{aligned} \\
\end{array}$ & \begin{tabular}{|c|}
0.00079 \\
23.8 \\
\end{tabular} & \begin{tabular}{|c|}
0.00460 \\
4.64 \\
\end{tabular} & $\begin{array}{c}0.0100 \\
2.06 \\
\end{array}$ & $\begin{array}{c}0.0142 \\
0.66\end{array}$ & - & - & $\begin{array}{c}0.00756 \\
10.5\end{array}$ & $\begin{array}{c}0.0129 \\
2.39\end{array}$ \\
\hline$(20-40) s \quad H z$ & - & 0.051 & 0.00978 & - & 0.00222 & - & 0.00733 & 0.0138 \\
\hline$(30-50) s \quad H z$ & - & 0.00400 & 0.0100 & 0.0151 & 0.00133 & 0.00667 & 0.00933 & \\
\hline $\begin{array}{r}(40-100) s \mathrm{~Hz} \\
n T\end{array}$ & - & 0.00578 & $\begin{array}{c}0.0102 \\
1.00 \\
\end{array}$ & $\begin{array}{c}0.0142 \\
0.564 \\
\end{array}$ & 0.00111 & - & \begin{tabular}{|c|}
0.00866 \\
2.71 \\
\end{tabular} & $\begin{array}{c}0.0129 \\
1.94 \\
\end{array}$ \\
\hline $\begin{array}{r}(80-300) s \mathrm{~Hz} \\
n T\end{array}$ & & \begin{tabular}{|c|}
0.00489 \\
4.09 \\
\end{tabular} & $\begin{array}{c}0.0100 \\
1.93 \\
\end{array}$ & & 0.00200 & - & \begin{tabular}{|c|}
0.00756 \\
10.6 \\
\end{tabular} & 0.0129 \\
\hline Time $h r: \min$ & \multicolumn{4}{|c|}{$1: 30-1: 45$} & \multicolumn{4}{|c|}{$1: 35-1: 50$} \\
\hline $\begin{array}{r}\text { Unfiltered. } \begin{array}{r}H z \\
n T\end{array}\end{array}$ & \begin{tabular}{|c|}
0.00143 \\
116
\end{tabular} & $\begin{array}{c}0.00511 \\
31.4\end{array}$ & $\begin{array}{c}0.0102 \\
6.60\end{array}$ & $\begin{array}{c}0.0149 \\
6.50\end{array}$ & $\begin{array}{c}0.00032 \\
95.1\end{array}$ & $\begin{array}{c}0.00533 \\
26.4\end{array}$ & \begin{tabular}{|c|}
0.00800 \\
7.60 \\
0.0104 \\
9.60 \\
\end{tabular} & - \\
\hline$(20-40) s \quad H z$ & 0.00133 & 0.00511 & 0.0102 & 0.0135 & 0.00200 & 0.00533 & 0.00822 & \begin{tabular}{|l|}
0.0127 \\
0.0151 \\
\end{tabular} \\
\hline$(30-50) s \quad H z$ & 0.00133 & 0.00422 & 0.0980 & 0.0131 & 0.00311 & - & 0.0102 & - \\
\hline $\begin{array}{r}(40-100) s \mathrm{~Hz} \\
n T \\
\end{array}$ & 0.00156 & 0.0067 & $\begin{array}{c}0.0100 \\
3.27 \\
\end{array}$ & \begin{tabular}{|c|}
0.0149 \\
6.11 \\
\end{tabular} & & 0.0467 & \begin{tabular}{|c|}
0.0104 \\
5.25 \\
\end{tabular} & - \\
\hline $\begin{array}{r}(80-300) s H z \\
n T\end{array}$ & 0.00133 & \begin{tabular}{|c|}
0.00489 \\
24.7
\end{tabular} & $\begin{array}{c}0.102 \\
6.23\end{array}$ & - & & \begin{tabular}{|c|}
0.00533 \\
23.3
\end{tabular} & \begin{tabular}{|c|}
0.00800 \\
7.89 \\
0.104 \\
8.51 \\
\end{tabular} & \\
\hline
\end{tabular}


Table A-II. (continued).

\begin{tabular}{|c|c|c|c|c|c|c|c|c|}
\hline Time $h r: \min$ & \multicolumn{4}{|c|}{$1: 40-1: 55$} & \multicolumn{4}{|c|}{$1: 45-2: 00$} \\
\hline Filter $\quad \mathrm{F}, \mathrm{Hz}$ & $\overline{F_{0, \text { max }}}$ & $F_{1, \text { max }}$ & $\overline{F_{2, \max }}$ & $F_{3, \max }$ & $\overline{F_{0, \text { max }}}$ & $\overline{F_{1, \max }}$ & $F_{2, \max }$ & $F_{3, \max }$ \\
\hline $\begin{array}{r}\text { Unfiltered. } \begin{array}{r}H z \\
n T\end{array} \\
\end{array}$ & $\begin{array}{c}0.00127 \\
65.1\end{array}$ & $\begin{array}{c}0.00533 \\
25.1\end{array}$ & $\begin{array}{l}- \\
-\end{array}$ & $\begin{array}{c}0.0131 \\
3.95\end{array}$ & $\begin{array}{l}- \\
-\end{array}$ & $\begin{array}{c}0.00667 \\
2.00\end{array}$ & - & $\begin{array}{c}0.0131 \\
1.33\end{array}$ \\
\hline$(20-40) s \quad H z$ & - & 0.00600 & - & - & 0.0289 & 0.00667 & - & 0.0142 \\
\hline$(30-50) s \quad H z$ & 0.00378 & - & 0.0102 & - & - & - & 0.00867 & $\begin{array}{l}0.0122 \\
0.0142\end{array}$ \\
\hline $\begin{array}{r}(40-100) s \mathrm{~Hz} \\
n T\end{array}$ & 0.00267 & - & $\begin{array}{c}0.00844 \\
2.93 \\
\end{array}$ & $\begin{array}{c}0.0131 \\
3.30\end{array}$ & $\begin{array}{c}0.00311 \\
-\end{array}$ & $\begin{array}{c}0.00622 \\
-\end{array}$ & - & $\begin{array}{c}0.0131 \\
1.22\end{array}$ \\
\hline $\begin{array}{r}(80-300) s \mathrm{~Hz} \\
n T \\
\end{array}$ & - & \begin{tabular}{|c|}
0.00600 \\
22.2 \\
\end{tabular} & - & 0.0131 & 0.00289 & $\begin{array}{c}0.00667 \\
2.12\end{array}$ & $\begin{array}{c}0.0113 \\
0.662\end{array}$ & $\begin{array}{c}0.0131 \\
-\end{array}$ \\
\hline Time $h r: \min$ & \multicolumn{4}{|c|}{$1: 50-2: 05$} & \multicolumn{4}{|c|}{$1: 55-2: 10$} \\
\hline 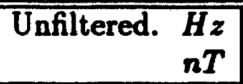 & $\begin{array}{c}0.00095 \\
75.1\end{array}$ & - & $\begin{array}{c}0.00978 \\
6.85\end{array}$ & - & $\begin{array}{c}0.00127 \\
77.5\end{array}$ & $\begin{array}{c}0.00467 \\
8.75\end{array}$ & $\begin{array}{c}0.00933 \\
15.0\end{array}$ & $\begin{array}{c}0.0131 \\
2.83\end{array}$ \\
\hline$(20-40) s \quad H z$ & - & - & 0.00866 & - & 0.00067 & 0.00422 & 0.00867 & - \\
\hline$(30-50) s \quad H z$ & - & - & 0.0100 & - & 0.00089 & 0.00422 & 0.00100 & - \\
\hline $\begin{array}{r}(40-100) s \mathrm{~Hz} \\
n T\end{array}$ & - & - & $\begin{array}{l}0.0111 \\
3.55\end{array}$ & - & 0.00111 & - & $\begin{array}{c}0.00955 \\
6.32\end{array}$ & $\begin{array}{c}0.0129 \\
2.34\end{array}$ \\
\hline $\begin{array}{r}(80-300) s z \\
n T \\
n T\end{array}$ & & - & $\begin{array}{c}0.00933 \\
6.76 \\
\end{array}$ & & 0.00089 & $\begin{array}{c}0.00422 \\
7.87\end{array}$ & $\begin{array}{c}0.00911 \\
14.7\end{array}$ & 0.0133 \\
\hline Time $h r: \min$ & \multicolumn{4}{|c|}{$2: 00-2: 15$} & \multicolumn{4}{|c|}{$2: 05-2: 20$} \\
\hline 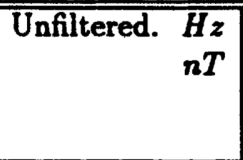 & $\begin{array}{c}0.00095 \\
15.0\end{array}$ & - & $\begin{array}{c}0.00756 \\
11.4 \\
0.113 \\
9.68\end{array}$ & $\begin{array}{c}0.0147 \\
7.59\end{array}$ & - & $\begin{array}{c}0.00467 \\
50.7\end{array}$ & $\begin{array}{c}0.00889 \\
23.1\end{array}$ & $\begin{array}{c}0.0131 \\
8.70\end{array}$ \\
\hline$(20-40) \mathrm{s} \quad \mathrm{Hz}$ & $=$ & 0.00356 & 0.00711 & - & - & 0.00467 & 0.00889 & 0.0133 \\
\hline$(30-50) s \quad H z$ & - & 0.00400 & 0.0104 & - & - & 0.00422 & 0.00933 & - \\
\hline $\begin{array}{r}(40-100) s \mathrm{~Hz} \\
n T\end{array}$ & 0.00156 & - & $\begin{array}{c}0.00800 \\
2.78 \\
0.111 \\
6.12 \\
\end{array}$ & $\begin{array}{c}0.0147 \\
6.91\end{array}$ & $\begin{array}{c}0.00067 \\
-\end{array}$ & 0.00511 & $\begin{array}{l}0.00933 \\
8.22\end{array}$ & $\begin{array}{c}0.0133 \\
7.62\end{array}$ \\
\hline $\begin{array}{r}(80-300) s \mathrm{~Hz} \\
n T\end{array}$ & - & $\begin{array}{c}0.00378 \\
11.9\end{array}$ & $\begin{array}{c}0.00778 \\
11.7 \\
0.0111 \\
7.83\end{array}$ & - & - & $\begin{array}{c}0.00467 \\
38.0\end{array}$ & $\begin{array}{c}0.00889 \\
23.2\end{array}$ & 0.0133 \\
\hline Time $h r: \min$ & \multicolumn{4}{|c|}{$2: 10-2: 25$} & \multicolumn{4}{|c|}{$2: 15-2: 30$} \\
\hline $\begin{array}{ll}\text { Unfiltered. } & \mathrm{Hz} \\
& n T \\
\end{array}$ & $\begin{array}{c}0.00159 \\
97.0 \\
\end{array}$ & - & $\begin{array}{c}0.00933 \\
19.1 \\
\end{array}$ & $\begin{array}{c}0.0147 \\
12.8 \\
\end{array}$ & - & $\begin{array}{c}0.00578 \\
32.0 \\
\end{array}$ & $\begin{array}{c}0.0107 \\
29.2 \\
\end{array}$ & - \\
\hline$(20-40) s \quad H z$ & 0.00333 & - & 0.00911 & 0.0135 & 0.00289 & 0.00578 & - & 0.0133 \\
\hline$(30-50) \mathrm{s} \quad \mathrm{Hz}$ & 0.00333 & - & 0.00955 & 0.0129 & 0.00333 & 0.00578 & 0.0104 & 0.0136 \\
\hline $\begin{array}{r}(40-100) s \mathrm{~Hz} \\
n T\end{array}$ & & $\begin{array}{c}0.00511 \\
- \\
\end{array}$ & $\begin{array}{c}0.00933 \\
7.87\end{array}$ & $\begin{array}{c}0.0149 \\
11.6\end{array}$ & - & - & - & $\begin{array}{c}0.0127 \\
17.8\end{array}$ \\
\hline $\begin{array}{r}(80-300) s \mathrm{~Hz} \\
n T \\
\end{array}$ & 0.00333 & - & $\begin{array}{c}0.00933 \\
18.7 \\
\end{array}$ & 0.0144 & 0.00289 & $\begin{array}{c}0.00578 \\
29.4 \\
\end{array}$ & $\begin{array}{c}-0.0104 \\
25.1 \\
\end{array}$ & - \\
\hline
\end{tabular}


Table A-II. (continued).

\begin{tabular}{|c|c|c|c|c|c|c|c|c|}
\hline Time $h r: \min$ & \multicolumn{4}{|c|}{$2: 20-2: 35$} & \multicolumn{4}{|c|}{$2: 25-2: 40$} \\
\hline Filter $\quad \mathrm{F}, \mathrm{Hz}$ & $F_{0, \text { mex }}$ & $\bar{F}_{1, \text { max }}$ & $F_{2, \max }$ & $F_{3, \max }$ & $\overline{F_{0, \max }}$ & $F_{1, \max }$ & $\overline{F_{2, \max }}$ & $F_{3, \max }$ \\
\hline $\begin{array}{cc}\text { Unfiltered. } & H z \\
n T\end{array}$ & $\begin{array}{l}- \\
-\end{array}$ & $\begin{array}{l}- \\
-\end{array}$ & $\begin{array}{l}- \\
-\end{array}$ & $\begin{array}{c}0.0136 \\
27.1\end{array}$ & $\begin{array}{c}0.00159 \\
21.7\end{array}$ & $\begin{array}{c}0.00533 \\
25.3\end{array}$ & $\begin{array}{c}0.0111 \\
15.3\end{array}$ & $\begin{array}{c}0.0149 \\
7.80\end{array}$ \\
\hline$(20-40) s \quad H z$ & - & 0.00444 & - & 0.0133 & 0.00200 & 0.00511 & - & 0.0140 \\
\hline$(30-50) s \quad H z$ & 0.00311 & - & 0.0102 & 0.0133 & 0.00200 & 0.00533 & - & 0.0138 \\
\hline $\begin{array}{r}(40-100) s \mathrm{~Hz} \\
n T\end{array}$ & 0.00244 & - & $\overline{-}$ & $\begin{array}{c}0.138 \\
23.4\end{array}$ & 0.00200 & - & \begin{tabular}{|c|}
0.00800 \\
3.18 \\
0.0111 \\
9.65
\end{tabular} & $\begin{array}{c}0.0149 \\
7.96\end{array}$ \\
\hline $\begin{array}{r}(80-300) s \mathrm{~Hz} \\
n T \\
\end{array}$ & - & $\begin{array}{c}0.00444 \\
41.4 \\
\end{array}$ & $\begin{array}{c}0.0113 \\
13.6 \\
\end{array}$ & - & 0.0200 & \begin{tabular}{|c|}
0.00511 \\
22.4 \\
\end{tabular} & \begin{tabular}{|c|}
0.0111 \\
12.03 \\
\end{tabular} & 0.147 \\
\hline Time $h r: \min$ & \multicolumn{4}{|c|}{$2: 30-2: 45$} & \multicolumn{4}{|c|}{$2: 35-2: 50$} \\
\hline 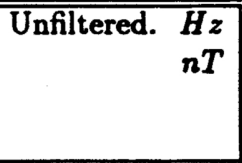 & - & $\begin{array}{c}0.00533 \\
25.0\end{array}$ & $\begin{array}{c}0.00889 \\
15.2\end{array}$ & - & $\begin{array}{c}0.00127 \\
138\end{array}$ & \begin{tabular}{|c|}
0.00444 \\
6.32 \\
0.00667 \\
5.79
\end{tabular} & $\begin{array}{c}0.0100 \\
4.25\end{array}$ & $\begin{array}{c}0.0140 \\
1.80\end{array}$ \\
\hline$(20-40) \mathrm{s} \quad \mathrm{Hz}$ & - & \begin{tabular}{|l|}
0.00533 \\
\end{tabular} & 0.00844 & - & \begin{tabular}{|l|}
0.00378 \\
\end{tabular} & 0.00667 & - & 0.0138 \\
\hline$(30-50) s \quad H z$ & - & 0.00533 & 0.0102 & - & - & \begin{tabular}{|l|}
0.00400 \\
0.00689 \\
\end{tabular} & 0.0102 & 0.0131 \\
\hline $\begin{array}{r}(40-100) s \mathrm{~Hz} \\
n T\end{array}$ & - & - & $\begin{array}{c}0.0978 \\
6.83 \\
\end{array}$ & - & - & - & $\begin{array}{c}0.0102 \\
2.23 \\
\end{array}$ & $\begin{array}{c}0.0140 \\
1.66\end{array}$ \\
\hline $\begin{array}{r}(80-300) s \mathrm{~Hz} \\
n T \\
\end{array}$ & & \begin{tabular}{|c|}
0.00533 \\
21.9 \\
\end{tabular} & $\begin{array}{c}0.00889 \\
15.1 \\
\end{array}$ & & \begin{tabular}{|c|}
0.00378 \\
5.27 \\
\end{tabular} & \begin{tabular}{|c|}
0.00667 \\
5.86 \\
\end{tabular} & - & 0.0142 \\
\hline Time $h r: \min$ & \multicolumn{4}{|c|}{$2: 40-2: 55$} & \multicolumn{4}{|c|}{$2: 45-3: 00$} \\
\hline $\begin{array}{rr}\text { Unfiltered. } & \mathrm{Hz} \\
& n T\end{array}$ & - & - & $\begin{array}{c}0.00711 \\
4.82 \\
0.0109 \\
7.10 \\
\end{array}$ & $\begin{array}{c}0.0151 \\
1.25\end{array}$ & $\begin{array}{c}0.00158 \\
17.8\end{array}$ & $\begin{array}{c}0.00467 \\
10.4\end{array}$ & $\begin{array}{c}0.00711 \\
12.4\end{array}$ & $\because$ \\
\hline $\begin{array}{c}(20-40) s \quad H z \\
-\end{array}$ & - & 0.00422 & $\begin{array}{c}0.00711 \\
0.104 \\
\end{array}$ & 0.0129 & 0.00178 & 0.00444 & 0.00711 & - \\
\hline$(30-50) s \quad H z$ & - & 0.00422 & 0.0104 & - & 0.00200 & 0.00466 & 0.0100 & - \\
\hline $\begin{array}{r}(40-100) s H_{z} \\
n T\end{array}$ & - & - & $\begin{array}{c}0.00698 \\
0.78 \\
0.0109 \\
0.78\end{array}$ & $\begin{array}{c}0.0151 \\
1.18\end{array}$ & 0.00244 & - & $\begin{array}{c}0.00822 \\
2.38\end{array}$ & - \\
\hline $\begin{array}{r}(80-300) s \mathrm{~Hz} \\
n T\end{array}$ & & \begin{tabular}{|c|}
0.00422 \\
8.21
\end{tabular} & \begin{tabular}{|c|}
0.00711 \\
5.08 \\
0.00107 \\
5.92 \\
\end{tabular} & - & 0.00178 & \begin{tabular}{|c|}
0.00444 \\
9.78
\end{tabular} & \begin{tabular}{|c|}
0.00711 \\
12.6
\end{tabular} & 0.0147 \\
\hline
\end{tabular}




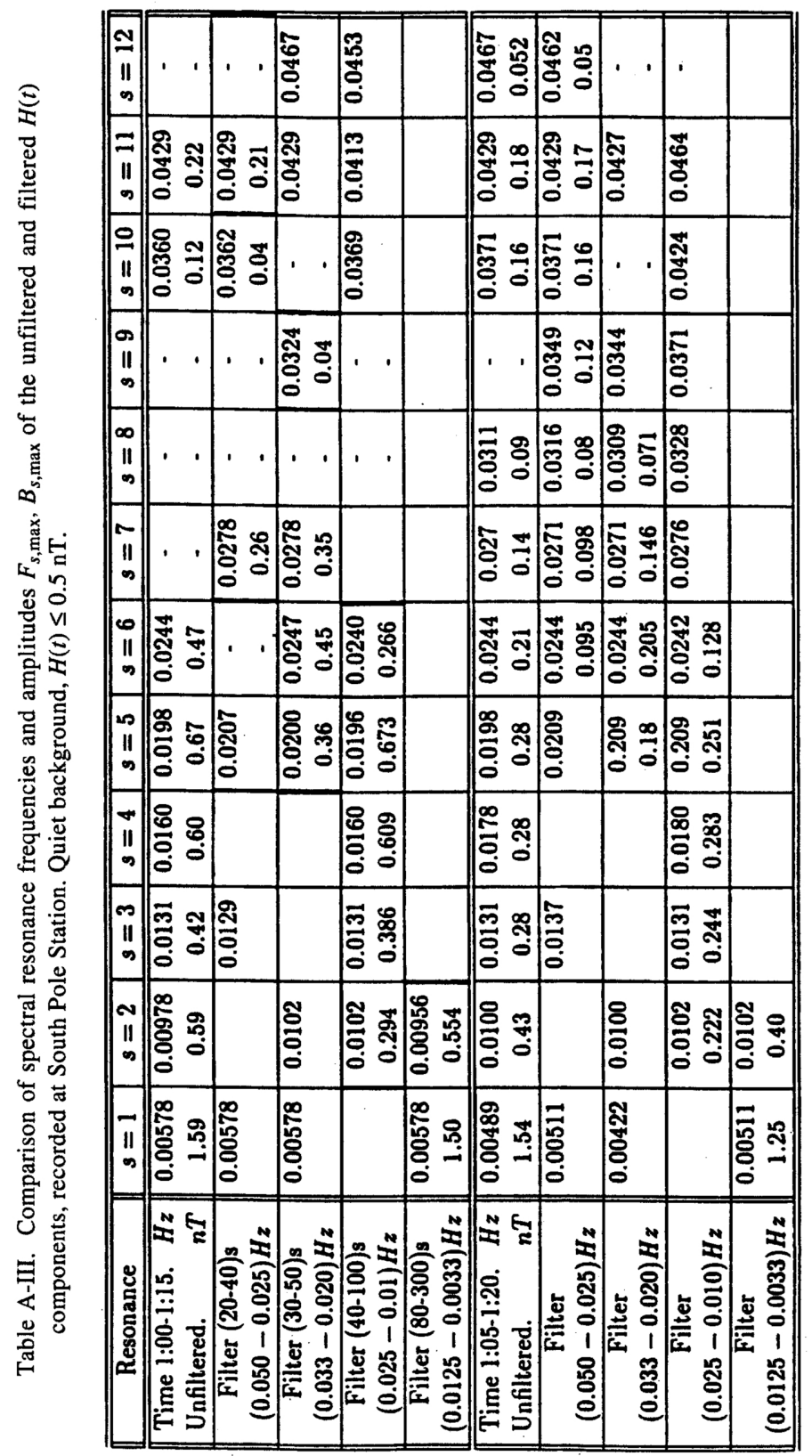




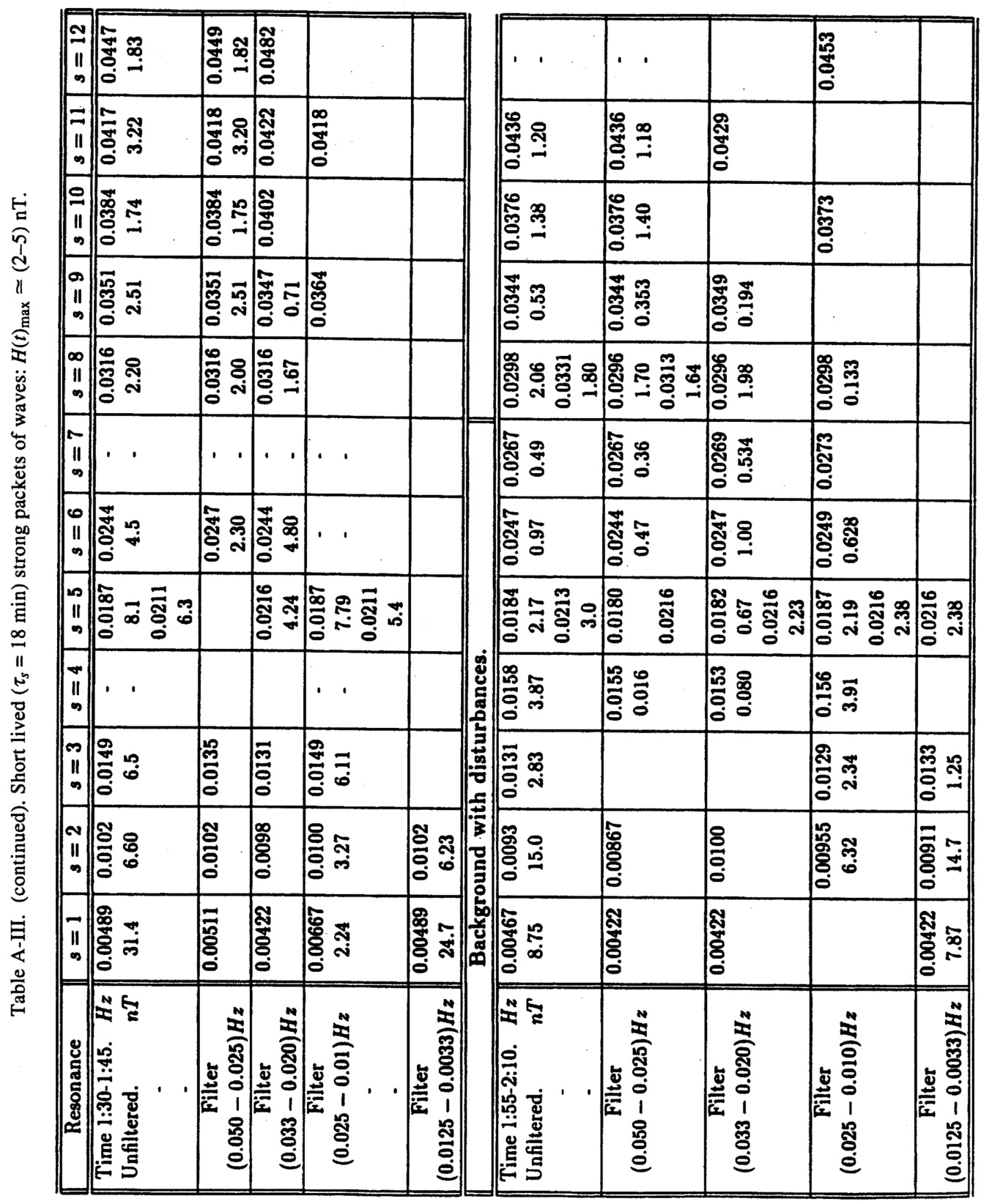




\begin{tabular}{|c|c|c|c|c|c|c|c|c|c|c|c|c|c|c|c|}
\hline $\begin{array}{l}-9 \\
\text { II } \\
\text { क }\end{array}$ & 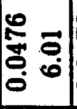 & $\mid \begin{array}{ll}0 & 0 \\
& 0 \\
0 & 8 \\
0 & 0 \\
0 & 0\end{array}$ & : & 足 & & 芯 & 葋 & $\begin{array}{l}5 \\
5 \\
0 \\
0 \\
0 \\
0\end{array}$ & : & & 勇 & 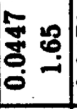 & $\mid \begin{array}{l}5 \\
\\
0 \\
0 \\
0\end{array}$ & 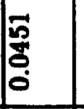 & \\
\hline$=$ & 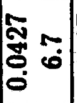 & 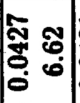 & है: & & & 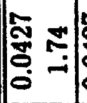 & స్ำ & 矛 & 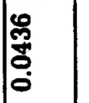 & & $\mid$\begin{tabular}{cc|}
0 & 0 \\
\multirow{2}{*}{} & 0 \\
0 & 0 \\
0 & 0
\end{tabular} & 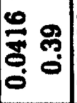 & | & : & \\
\hline $\begin{array}{l}0 \\
11 \\
\infty\end{array}$ & 1. & . . & 禀 & E. & & . ' & $1 \cdot 1$ & & & & 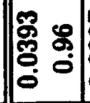 & $\begin{array}{ll}5 \\
\bar{\delta} & 8 \\
0 & 8 \\
0\end{array}$ & & & \\
\hline $\begin{array}{l}0 \\
\text { II } \\
0 \\
\end{array}$ & & 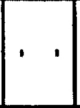 & ' & 串 & & ' & 1. &. & סִ & & 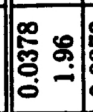 & 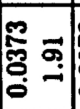 & 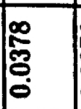 & 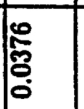 & \\
\hline $\begin{array}{l}\infty \\
11 \\
\infty \\
\end{array}$ & $\mid \begin{array}{cc}0 \\
0 \\
0 & 0 \\
0 & 0 \\
\end{array}$ & 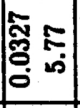 & 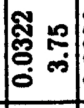 & 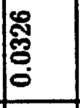 & & 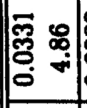 & 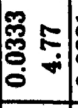 & 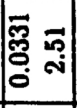 & 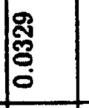 & & 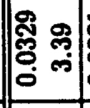 & 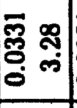 & 局 & 俤 & \\
\hline - & 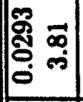 & $\cdot$. & 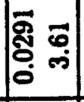 & & & 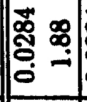 & 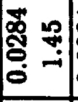 & 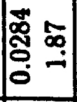 & 依 & & & . & & 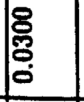 & \\
\hline $\begin{array}{l}0 \\
11 \\
0 \\
\end{array}$ & 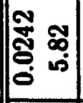 & 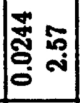 & 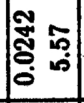 & . & & 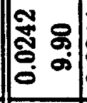 & 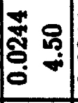 & 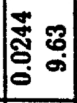 & 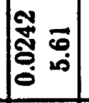 & & 茟 & 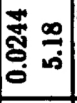 & 范 & 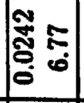 & \\
\hline a & 总 & & 1 & 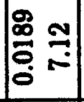 & & $\mid \begin{array}{ll}\infty & \\
0 & 0 \\
0 & 0 \\
0 & 0 \\
0\end{array}$ & ' & 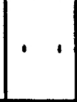 & 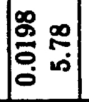 & & $\cdot$ & & 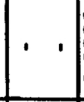 & 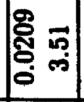 & \\
\hline $\begin{array}{l}\infty \\
11 \\
\infty\end{array}$ & $\cdot 1$ & & & $\begin{array}{ll}1 & 1 \\
1 & 1\end{array}$ & & & 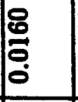 & 。 & $\cdot$. & & 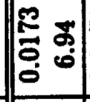 & E & \begin{tabular}{|l|}
$E$ \\
0 \\
0 \\
0 \\
\end{tabular} & {$\left[\begin{array}{ll}0 & 0 \\
\hdashline & 0 \\
0 & 0 \\
0 & -1\end{array}\right.$} & E్ \\
\hline $\begin{array}{c}\infty \\
11 \\
0 \\
\end{array}$ & $\mid \begin{array}{cc}\vec{m} & 0 \\
0 & 0 \\
0 & \infty \\
0\end{array}$ & $\mid \begin{array}{cc}0 \\
0 \\
0\end{array}$ & & 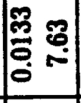 & 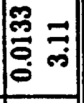 & 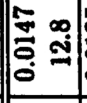 & . & 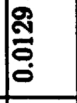 & 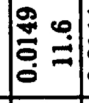 & 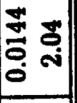 & & 粱 & $\mid \begin{array}{l}\mathscr{y} \\
0 \\
0 \\
0 \\
0\end{array}$ & 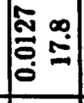 & \\
\hline $\begin{array}{l}0 \\
11 \\
0\end{array}$ & 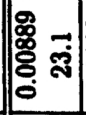 & 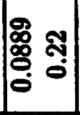 & 粱 & 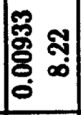 & 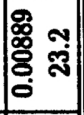 & 确 & 局 & 笭 & 绨 & 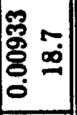 & 突 & & 苨 & 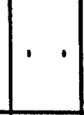 & : \\
\hline II & 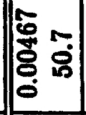 & 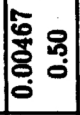 & స్తి & 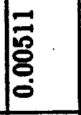 & 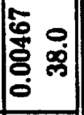 & . & & & 俤 & . & 点 & 萬 & 冓 & & 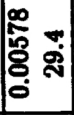 \\
\hline $\mid \begin{array}{l}\text { 总 } \\
\mathbb{2}\end{array}$ & 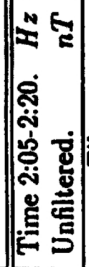 & 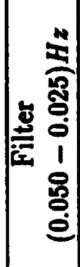 & 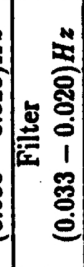 & 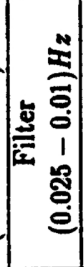 & 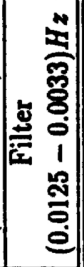 & 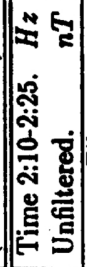 & 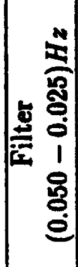 & 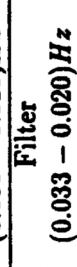 & 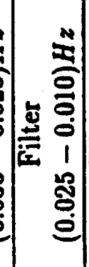 & 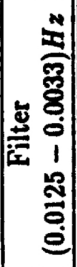 & 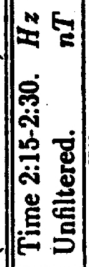 & 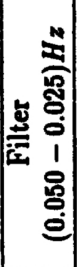 & 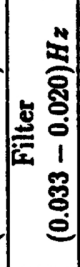 & 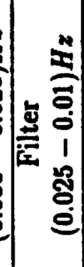 & 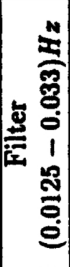 \\
\hline
\end{tabular}




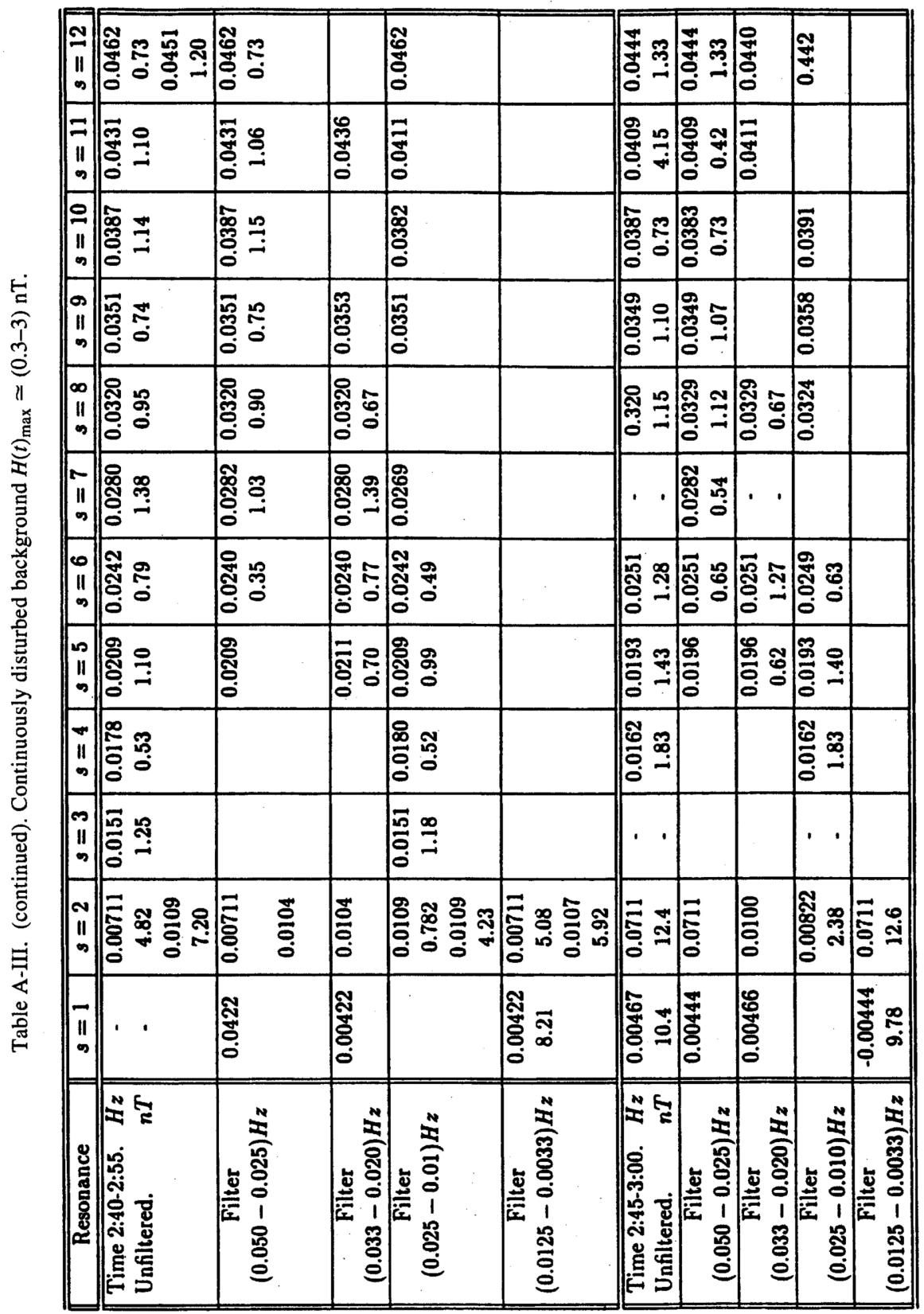


Table A-IV. Frequencies and amplitudes $F_{s, \max }, B_{s, \max }$ of the spectra in time intervals $\Delta t_{s}=15$ min of the filtered $H(t)$ component of the magnetic field by a filter $\Delta t_{f}=(30-40)$ sec.

\begin{tabular}{|c|c|c|c|c|c|c|c|c|}
\hline \multirow{3}{*}{$\begin{array}{c}\begin{array}{c}\text { Intervals } \\
\text { of time } \\
\Delta t .\end{array} \\
\text { hour.min } \\
1.00-1.15\end{array}$} & \multicolumn{4}{|c|}{ N.P.,Iqaluit, Canada, $L=13$} & \multicolumn{4}{|c|}{ S.P., Amundsen Scott, $L=13$} \\
\hline & \multicolumn{2}{|c|}{$\begin{array}{l}F_{6}, F_{7}, H_{z} \\
B_{6}, B_{7}, n T\end{array}$} & \multirow{2}{*}{\begin{tabular}{|c|}
$F_{8}, H z$ \\
$B_{B}, n T$ \\
0.0300 \\
0.115
\end{tabular}} & \multirow{2}{*}{$\begin{array}{l}F_{9, ~}, z z \\
B_{9}, n T \\
0.0344 \\
0.116 \\
0.0329 \\
0.112\end{array}$} & \multicolumn{2}{|c|}{$\begin{array}{l}F_{6}, F_{7}, H_{z} \\
B_{6}, B_{7}, n T\end{array}$} & \multirow{2}{*}{$\begin{array}{c}F_{8}, \mathrm{~Hz} \\
B_{8}, n T \\
0.0324 \\
0.043\end{array}$} & \multirow{2}{*}{$\begin{array}{c}F_{0, H z} \\
B_{9, n T} \\
-\end{array}$} \\
\hline & - & $\begin{array}{c}0.0264 \\
0.78\end{array}$ & & & 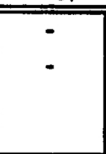 & $\begin{array}{l}0.0278 \\
0.349\end{array}$ & & \\
\hline $1.05-1.20$ & - & $\begin{array}{c}0.0276 \\
1.22 \\
\end{array}$ & - & 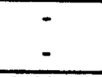 & $\begin{array}{c}0.0244 \\
0.076 \\
\end{array}$ & $\begin{array}{c}0.0273 \\
0.133 \\
\end{array}$ & $\begin{array}{c}0.0309 \\
0.079\end{array}$ & - \\
\hline $1.07-1.22$ & $\begin{array}{c}0.0251 \\
0.319 \\
\end{array}$ & $\begin{array}{c}0.0284 \\
0.539 \\
\end{array}$ & $\begin{array}{c}0.0311 \\
0.425 \\
\end{array}$ & $\begin{array}{c}0.0344 \\
0.090\end{array}$ & - & $\begin{array}{c}0.0269 \\
0.092\end{array}$ & - & $\begin{array}{l}.0333 \\
.0530\end{array}$ \\
\hline $1.10-1.25$ & $\begin{array}{c}0.0244 \\
0.255 \\
\end{array}$ & $\begin{array}{c}0.0267 \\
0.156 \\
\end{array}$ & $\begin{array}{c}0.0293 \\
0.287 \\
\end{array}$ & $\begin{array}{l}0.0313 \\
0.393 \\
\end{array}$ & $\begin{array}{c}0.0236 \\
0.021 \\
\end{array}$ & $\begin{array}{c}0.0267 \\
0.052 \\
\end{array}$ & $\begin{array}{c}0.0296 \\
0.057 \\
\end{array}$ & $\begin{array}{l}0.0338 \\
0.032\end{array}$ \\
\hline 1. & $\begin{array}{c}0.0242 \\
0.198 \\
\end{array}$ & $\begin{array}{c}0.0290 \\
0.604 \\
\end{array}$ & - & $\begin{array}{l}0.0327 \\
0.168\end{array}$ & \begin{tabular}{c|}
0.0231 \\
0.021
\end{tabular} & $\begin{array}{c}0.0280 \\
0.126\end{array}$ & \begin{tabular}{c|}
0.0316 \\
0.108
\end{tabular} & - \\
\hline $1.20-1.35$ & $\begin{array}{c}0.0244 \\
0.215 \\
\end{array}$ & $\begin{array}{c}0.0280 \\
0.860\end{array}$ & - & & - & & \begin{tabular}{c|}
0.0320 \\
0.243
\end{tabular} & - \\
\hline 1.22 & - & $\begin{array}{c}0.280 \\
2.20\end{array}$ & $\begin{array}{c}0.0307 \\
1.86 \\
\end{array}$ & $\begin{array}{c}0.0353 \\
0.128\end{array}$ & $\begin{array}{l}0.0226 \\
0.050\end{array}$ & $\begin{array}{c}0.0256 \\
0.126\end{array}$ & \begin{tabular}{c|}
0.0293 \\
0.404
\end{tabular} & $\begin{array}{l}0.0331 \\
0.108\end{array}$ \\
\hline 1.2 & - & $\begin{array}{c}0.0264 \\
5.19\end{array}$ & $\begin{array}{c}0.0307 \\
4.68\end{array}$ & - &. & $\begin{array}{c}0.0256 \\
0.786\end{array}$ & \begin{tabular}{c|}
0.0307 \\
0.836
\end{tabular} & $\begin{array}{l}0.0324 \\
0.070\end{array}$ \\
\hline $1.30-1.45$ & - & $\begin{array}{c}0.0262 \\
6.74\end{array}$ & $\begin{array}{c}0.0287 \\
7.70 \\
0.030 \\
2.27 \\
\end{array}$ & - & 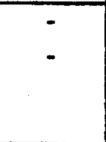 & $\begin{array}{c}0.0251 \\
2.08\end{array}$ & $\begin{array}{c}0.0315 \\
1.90\end{array}$ & $\begin{array}{l}0.0344 \\
0.505\end{array}$ \\
\hline $1.35-1.50$ & $\begin{array}{c}0.0247 \\
1.12 \\
\end{array}$ & $\begin{array}{c}0.0293 \\
0.88 \\
\end{array}$ & $\begin{array}{c}0.0315 \\
1.09 \\
\end{array}$ & $\begin{array}{l}0.0347 \\
0.211 \\
\end{array}$ & - & $\begin{array}{c}0.0271 \\
2.44\end{array}$ & \begin{tabular}{|c|}
0.0313 \\
1.60 \\
\end{tabular} & - \\
\hline $1.37-1.52$ & $\begin{array}{l}0.0240 \\
0.311 \\
\end{array}$ & $\begin{array}{c}0.0269 \\
0.379\end{array}$ & $\begin{array}{c}0.0317 \\
0.76 \\
\end{array}$ & $\begin{array}{l}0.0355 \\
0.041\end{array}$ & 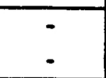 & $\begin{array}{c}0.0271 \\
2.88\end{array}$ & \begin{tabular}{c|}
0.0302 \\
1.80
\end{tabular} & $\begin{array}{c}0.0344 \\
0.518\end{array}$ \\
\hline $1.40-1.55$ & $\begin{array}{c}0.0229 \\
0.137 \\
\end{array}$ & $\begin{array}{c}0.0267 \\
0.568 \\
\end{array}$ & $\begin{array}{c}0.0311 \\
1.07 \\
\end{array}$ & - & - & $\begin{array}{c}0.0264 \\
1.76\end{array}$ & \begin{tabular}{c|}
0.0300 \\
1.56
\end{tabular} & 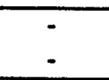 \\
\hline $1.45-2.00$ & 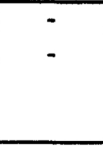 & - & $\begin{array}{c}0.0304 \\
0.847\end{array}$ & $\begin{array}{c}0.0338 \\
0.061\end{array}$ & $\begin{array}{c}0.0247 \\
0.234 \\
0.0244 \\
0.057\end{array}$ & $\begin{array}{c}0.0264 \\
0.198\end{array}$ & \begin{tabular}{c|}
0.0302 \\
0.417
\end{tabular} & $\begin{array}{c}0.0351 \\
0.081\end{array}$ \\
\hline $1.50-2.05$ & - & $\begin{array}{c}0.0287 \\
1.30\end{array}$ & - & $\begin{array}{c}0.0331 \\
0.45\end{array}$ & - & $\begin{array}{c}0.0295 \\
2.98\end{array}$ & - & - \\
\hline-2.07 & $\begin{array}{c}0.0250 \\
0.823\end{array}$ & - & $\begin{array}{c}0.0293 \\
2.10\end{array}$ & - & 5 & $\begin{array}{c}0.0297 \\
3.99\end{array}$ & . & - \\
\hline
\end{tabular}


Table A-IV. (continued).

\begin{tabular}{|c|c|c|c|c|c|c|c|c|}
\hline \multirow{3}{*}{\begin{tabular}{|c|}
$\begin{array}{c}\text { Intervals } \\
\text { of time } \\
\Delta t,\end{array}$ \\
$1.55-2.10$ \\
\end{tabular}} & \multicolumn{4}{|c|}{ N.P.,Iqaluit, Canada, $L=13$} & \multicolumn{4}{|c|}{ S.P., Amundsen Scott, $\bar{L}=13$} \\
\hline & \multicolumn{2}{|c|}{$\begin{array}{l}F_{6}, F_{7}, H_{z} \\
B_{6}, B_{7}, n T\end{array}$} & \multirow{2}{*}{$\begin{array}{c}F_{8}, H z \\
B_{8}, n T \\
0.0302 \\
2.23\end{array}$} & \multirow{2}{*}{$\begin{array}{c}F_{0, ~ H z} \\
B_{9, n T} \\
0.0377 \\
0.510\end{array}$} & \multicolumn{2}{|c|}{$\begin{array}{l}F_{6}, F_{7}, H z \\
B_{6}, B_{7}, n T\end{array}$} & \multirow{2}{*}{\begin{tabular}{|c|}
$F_{8}, H z$ \\
$B_{8}, n T$ \\
0.0293 \\
2.15
\end{tabular}} & \multirow{2}{*}{$\begin{array}{c}F_{9, H z} \\
B_{9, n T} \\
0.0351 \\
0.16\end{array}$} \\
\hline & $\begin{array}{c}0.0220 \\
0.203\end{array}$ & $\begin{array}{c}0.0273 \\
1.66 \\
\end{array}$ & & & $\begin{array}{c}0.0242 \\
0.50\end{array}$ & $\begin{array}{c}0.0267 \\
0.583\end{array}$ & & \\
\hline $2.00-2.15$ & - & $\begin{array}{c}0.0260 \\
2.43\end{array}$ & $\begin{array}{c}0.0298 \\
2.46\end{array}$ & . & $\begin{array}{c}0.0235 \\
0.535\end{array}$ & $\begin{array}{c}0.0291 \\
1.88\end{array}$ & $\begin{array}{c}0.0326 \\
1.28\end{array}$ & - \\
\hline $2.05-2.20$ & $\begin{array}{c}0.0244 \\
0.348\end{array}$ & $\begin{array}{c}0.0276 \\
0.415\end{array}$ & $\begin{array}{c}0.0300 \\
0.314\end{array}$ & $\begin{array}{l}0.0322 \\
0.321\end{array}$ & $\begin{array}{c}0.0244 \\
2.05 \\
\end{array}$ & $\begin{array}{c}0.0291 \\
3.77\end{array}$ & $\begin{array}{c}0.0322 \\
4.08\end{array}$ & - \\
\hline $2.07-2.22$ & $\begin{array}{c}0.0238 \\
0.30\end{array}$ & \begin{tabular}{|c|}
0.0277 \\
0.225
\end{tabular} & - & $\begin{array}{c}0.0316 \\
0.56\end{array}$ & $\begin{array}{c}0.0246 \\
2.50\end{array}$ & $\begin{array}{c}0.0282 \\
2.97\end{array}$ & $\begin{array}{c}0.0327 \\
2.95\end{array}$ & $\begin{array}{c}0.0360 \\
0.283\end{array}$ \\
\hline $2.10-2.25$ & $\begin{array}{c}0.0229 \\
0.213\end{array}$ & $\begin{array}{c}0.0257 \\
0.321\end{array}$ & $\begin{array}{c}0.0289 \\
0.32\end{array}$ & \begin{tabular}{c|}
0.0318 \\
0.845
\end{tabular} & $\begin{array}{c}0.0244 \\
3.70\end{array}$ & $\begin{array}{c}0.0284 \\
1.92\end{array}$ & $\begin{array}{c}0.0331 \\
2.58\end{array}$ & - \\
\hline $2.15-2.30$ & $\begin{array}{c}0.0249 \\
0.73\end{array}$ & $\begin{array}{c}0.0280 \\
1.17\end{array}$ & - & $\begin{array}{c}0.0324 \\
0.656\end{array}$ & $\begin{array}{c}0.0247 \\
4.30\end{array}$ & $\begin{array}{c}0.0296 \\
4.74\end{array}$ & $\begin{array}{c}0.0331 \\
2.06\end{array}$ & - \\
\hline $2.20-2.35$ & $\begin{array}{c}0.0224 \\
0.201\end{array}$ & $\begin{array}{c}0.0280 \\
1.14 \\
\end{array}$ & - & \begin{tabular}{c|}
0.0315 \\
0.953
\end{tabular} & - & $\begin{array}{c}0.0296 \\
4.74\end{array}$ & - & - \\
\hline 2. & - & $\begin{array}{c}0.0253 \\
1.16\end{array}$ & $\begin{array}{c}0.0289 \\
1.43\end{array}$ & - & - & $\begin{array}{c}0.0271 \\
4.57\end{array}$ & $\begin{array}{c}0.0307 \\
4.25\end{array}$ & $\begin{array}{c}0.0338 \\
0.859\end{array}$ \\
\hline $2.25-2.40$ & & $\begin{array}{c}0.0260 \\
2.26\end{array}$ & $\begin{array}{c}0.0307 \\
1.08\end{array}$ & - & $\begin{array}{c}0.0244 \\
1.52\end{array}$ & $\begin{array}{c}0.0278 \\
4.15\end{array}$ & - & - \\
\hline 2.30 & - & $\begin{array}{c}0.0260 \\
1.65\end{array}$ & $\begin{array}{c}0.0284 \\
0.880\end{array}$ & $\begin{array}{c}0.0320 \\
0.588\end{array}$ & $\begin{array}{c}0.0256 \\
2.13\end{array}$ & $\begin{array}{c}0.0289 \\
3.45\end{array}$ & $\begin{array}{c}0.0296 \\
3.25\end{array}$ & - \\
\hline 2.35 & 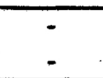 & $\begin{array}{c}0.0273 \\
0.466\end{array}$ & - & $\begin{array}{c}0.0318 \\
0.265\end{array}$ & $\begin{array}{c}0.0242 \\
0.35\end{array}$ & $\begin{array}{c}0.0273 \\
1.37\end{array}$ & $\begin{array}{c}0.0311 \\
0.792\end{array}$ & - \\
\hline $2.37-2.52$ & $\begin{array}{c}0.0249 \\
0.20\end{array}$ & \begin{tabular}{|c|}
0.0278 \\
0.376
\end{tabular} & $\begin{array}{c}0.0307 \\
0.231\end{array}$ & $\begin{array}{c}0.0329 \\
0.140\end{array}$ & 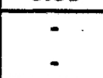 & $\begin{array}{c}0.0273 \\
1.60\end{array}$ & $\begin{array}{c}0.0311 \\
1.01\end{array}$ & $\begin{array}{c}0.0360 \\
0.038\end{array}$ \\
\hline $2.40-2.55$ & $\begin{array}{c}0.0244 \\
1.83\end{array}$ & $\begin{array}{c}0.0287 \\
0.60\end{array}$ & - & 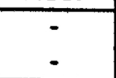 & $\begin{array}{c}0.0238 \\
0.25\end{array}$ & $\begin{array}{c}0.0282 \\
1.35\end{array}$ & $\begin{array}{c}0.0320 \\
0.77\end{array}$ & - \\
\hline $2.45-3.00$ & $\begin{array}{c}0.0235 \\
0.204\end{array}$ & \begin{tabular}{|c|}
0.0284 \\
0.753
\end{tabular} & - & $\begin{array}{c}0.0318 \\
0.557\end{array}$ & $\begin{array}{c}0.0255 \\
0.673\end{array}$ & $\begin{array}{c}0.0284 \\
0.702\end{array}$ & $\begin{array}{c}0.0324 \\
0.745\end{array}$ & - \\
\hline$\overline{\overline{\text { Mean } \bar{F}}}$ & 0.0240 & 0.0270 & 0.0307 & 0.0331 & 0.0242 & 0.0274 & 0.0309 & 0.0341 \\
\hline
\end{tabular}

\section{REFERENCES}

Alpert, Ya. L., On spectra and some properties of Pc-1 geomagnetic pulsations of a complex shape, Planet. Space Sci., 35, 1381, 1987.

Alpert, Ya. L. and D. S. Fligel, Propagation of ELF and VLF Waves near the Earth, 171 pp., Consultant Bureau, N.Y., London, 1970 (see pp. 74-79).

Alpert, Ya. L. and D. S. Fligel, Fourier analysis of geomagnetic micropulsation Pc-1, Planet. Space Sci., 33, 993, 1985; 35, 879, 1987.

Alpert, Ya. L. and L. J. Lanzerotti, Oscillatory nature of the magnetosphere, ELF resonances, background, 1998 (in preparation).

Alpert, Ya. L., D. S. Fligel, and A. A. Yaroslavtsev, Spectra of geomagnetic pulsation Pc-1 of complex shape and simulation of their generation process, Planet. Space Sci., 37, 391, 1989.

Alpert, Ya. L., L. J. Lanzerotti, D. J. Thompson, C. G. Maclennan, and A. Wolfe, Hydromagnetic background of the magnetosphere and gyroresonance swinging of a giant Pc-2 wave event, J. Geophys. Res., 98, 7571, 1993.

Alpert, Ya. L., L. J. Lanzerotti, and S. T. Rybachek, Oscillatory nature of the magnetosphere, III. Resonance oscillations. Some simulation, J. Geomag. Geoelectr., 49, this issue, S121-S130, 1997.

Belyaev, P. P., S. V. Polyakov, V. T. Rapoport, and N. Yu. Trachtengertz, About resonances of the magnetosphere, Geomagn. Aeron., 24, 383, 1984 (in Russian).

Brjunelli, B. E. and A. A. Namgaladze, Self-frequencies of the thyroidal magnetosphere, Geomagn. Aeron., 9, 763 , 1969 (in Russian). 
Chen, L. and A. Hasegawa, A theory of long-period magnetic pulsations, 1, Steady state excitation of filed line resonances, $J$. Geophys. Res., 79, 1024, 1974a.

Chen, L. and A. Hasegawa, A theory of long-period magnetic pulsations, 2, Impulse excitation of surface eigenmode, J. Geophys. Res., 79, 1033, 1974b.

Cummings, W. D., F. Masson, and P. J. Coleman, Characteristics of low frequency oscillations observed at ATS-1, J. Geophys. Res., 77, 748, 1962.

Dungey, J. W., Electrodynamics of the outer atmosphere, Penn. State Univ. Sci. Reports, \#1969, 1954.

Dungey, J. W., Hydromagnetic waves, in Physics of Geomagnetic Phenomena, edited by S. Matshushita and W. H. Campbell, 913 pp., Academic Press, N.Y., 1968.

Ershkovich, A. N. and A. A. Nusinov, Self-frequencies of the Earth's magnetic tail, Cosmic Investigations, 9, 470, 1971 (in Russian).

Fukunishi, H. and L. J. Lanzerotti, ULF pulsation evidence of the plasmapause, 1. Spectral studies of Pc-3 and Pc-4 pulsations near $L=4$, J. Geophys. Res., 79, 142, 1974a.

Fukunishi, H. and L. J. Lanzerotti, ULF pulsation evidence of the plasmapause, 2. Polarization studies of Pc3 and Pc4 pulsations near $L=4$ and at a latitude network in the conjugate region, J. Geophys. Res., 79, 4032, $1974 \mathrm{~b}$.

Gulelmi, A. V. and V. A. Troitskaya, Geomagnetic Pulsations and Diagnostic of the Magnetosphere, 208 pp., Publishing House Nauka, Moscow, 1973.

Kivelson, M. G. and D. J. Southwood, Resonant ULF waves: A new interpretation, Geophys. Res. Lett., 12, $49,1985$.

Kivelson, M. G. and D. J. Southwood, Coupling of global magnetospheric MHD eigenmodes to filed line resonances, J. Geophys. Res., 91, 4345, 1986.

Krylov, A. L. and A. Ye. Lifshits, Resonances of the magnetosphere, Fizika Zemli, No. 11, 3, 1983 (in Russian).

Lanzerotti, L. J., L. V. Medford, A. Hasegawa, and D. Lin, Large amplitude ion bounce wave in the magnetosphere near $L=3$, Geophys. Res. Lett., 10, 479, 1983.

Lanzerotti, L. J., L. V. Medford, and A. Meloni, Spatial structure of the ion bounce wave in the magnetosphere, J. Geophys. Res., 91, 1887, 1986.

Mandelshtam, L. I., Complete Collection of Works, Vol. IV, pp. 223-260, Lectures on oscillation, 1955 (in Russian).

McClay, J. F., On the resonance modes of a cavity and the dynamic properties of micropulsations, Planet. Space Sci., 74, 778, 1969.

McPherron, R. L., C. T. Russel, and P. J. Coleman, Fluctuating magnetic fields in the magnetosphere, 2, Space Sci. Rev. 13, 411, 1972.

Obayashi, T., Hydromagnetic whistlers, J. Geophys. Res., 70, 1069, 1965.

Orr, D. and J. A. D. Mathew, The variation of geomagnetic micropulsations periods with latitude and the plasmapause, Planet. Space Sci., 19, 897, 1973.

Patel, V. L., Low frequency hydro-magnetic waves in the magnetosphere, Planet. Space Sci., 13, 485, 1965.

Patel, V. L., Magnetospheric tail as a hydrodynamic wave guide, Phys. Rev. Lett., 26A, 556, 1968.

Poiyakov, S. V., V. T. Rapoport, and V. Yu. Trachtengertz, About resonances of the magnetosphere, IPFAN, Preprint \#23, 17, 1981 (in Russian).

Radoski, H. R., Highly asymmetric MHD resonances: The guided poloidol mode, J. Geophys. Res., 72, 4026, 1967 a.

Radoski, H. R., A note on oscillating field lines, J. Geophys. Res., 72, 4180, 1967b.

Radoski, H. R., A note on the problem of hydromagnetic resonances in the magnetosphere, Planet. Space Sci., $19,1012,1971$.

Rickard, G. J. and A. N. Wright, Alfven resonance excitation and fast wave propagation in magnetospheric wave guides, J. Geophys. Res., 99, 13, 455, 1994.

Russell, C. T., R. L. McPherron, and P. J. Coleman, Fluctuating magnetic fields in the magnetosphere: ELF and VLF fluctuations, 1, Space Sci. Rev., 12, 810, 1972.

Southwood, D. J., Comments on field line resonances and micropulsations, Geophys. J. Roy. Astr. Soc., 41, $425,1974$.

Southwood, D. J., Some features of the field line resonances in the magnetosphere, Planet. Space Sci., 22, 483, 1975.

Watanabe, T., Hydromagnetic oscillations of the outer ionosphere and geomagnetic pulsations, J. Geomag. Geoelectr., 10, 195, 1959 (Japan).

Watanabe, T., On the origin of geomagnetic pulsations, Sci. Reports, Tohoku Univ., 13, 127, 1961. 